UNIVERSIDADE DE BRASÍLIA - UnB

FACULDADE DE DIREITO

\title{
Regulação jurídica e empreendedorismo: \\ impactos jurídicos do conceito de empreendedorismo no grau de concentração regulatória normativa no setor de telecomunicações mediante estudo do caso Actium
}

André Moura Gomes

Matrícula: 04/12341

Brasília

Dezembro de 2009 
UNIVERSIDADE DE BRASÍLIA - UnB

FACULDADE DE DIREITO

\section{Regulação jurídica e empreendedorismo:}

impactos jurídicos do conceito de empreendedorismo no grau de concentração regulatória normativa no setor de telecomunicações mediante estudo do caso Actium

Monografia apresentada como requisito parcial para obtenção do grau de Bacharel em Direito da Universidade de Brasília - UnB, elaborada sob a orientação do Prof. Márcio Nunes Iorio Aranha Oliveira.

André Moura Gomes

Matrícula: 04/12341

Brasília

Dezembro de 2009 


\section{Agradecimentos}

Aos meus pais e familiares, por apoiarem minhas escolhas. À minha amada, por seu carinho e compreensão infinitos. Ao meu orientador, por seu companheirismo e sabedoria. Aos meus amigos, porque me estimulam a agir. Todos influenciaram este trabalho. 


\section{Resumo}

Este trabalho estuda a interação entre a regulação jurídica e o conceito de empreendedorismo, analisando seu significado institucional, e verificando o impacto de sua aplicação como argumento no caso "Actium", do setor de telecomunicações. O caso se refere a pedido de autorização para prestação de serviço de telecomunicações, indeferido pela Agência Nacional de Telecomunicações por ausência de previsão regulatória. O método de análise é o hermenêutico. $\mathrm{O}$ estudo segue este roteiro: no primeiro capítulo, demonstra-se que a variação na regulação jurídica sobre determinada atividade é determinada pelo grau de concentração regulatória, normativa e operacional, a ela aplicável. O conceito trabalhado por Herren Aguillar se refere à interpretação da atividade regulatória do Estado como um espectro de possibilidades de atuação, que oscila entre a abertura de espaços à iniciativa privada e intervenção estatal. No segundo capítulo, são apresentados os elementos funcionais do fenômeno do empreendedorismo, sistematizados por Michael Peneder, relacionando-o à assunção de risco, coordenação de mercado, difusão tecnológica, inovação etc., e é demonstrada sua relevância jurídica, em conexão com os princípios da livre iniciativa e livre concorrência. No terceiro capítulo, os fatos relevantes do caso "Actium" são descritos, e é feita análise das consequências jurídicas da aplicação do conceito de empreendedorismo ao caso, com destaque para a conformação do significado do princípio da isonomia no contexto. Por fim, o trabalho conclui que o conceito de empreendedorismo é juridicamente relevante, e sua aplicação pode produzir impacto no debate sobre o grau de concentração regulatória normativa aplicável à prestação de determinado serviço de telecomunicações.

Palavras-chave: Direito. Regulação. Telecomunicações. Empreendedorismo. Actium. 


\begin{abstract}
This work studies the interaction between legal regulation and the concept of entrepreneurship by analyzing its institutional meaning and verifying the impact of its use as a reason in a case from the telecommunications sector, the so-called "Actium" case. The case refers to a request for authorization to provide a telecommunications service, rejected by the National Telecommunications Agency as it ruled there was no regulatory support. The analysis uses the hermeneutic method. The paper follows this sequence: in the first chapter, we demonstrate that the legal regulation for a certain activity varies according to the applicable level of normative and operational regulatory concentration. This concept presented by Herren Aguillar refers to the interpretation of the State regulatory activity as a spectrum of possible ways of acting, varying between opening normative spheres to private actors and State intervention. In the second chapter, the functional elements of the entrepreneurship phenomenon as organized by Michael Peneder are presented, and connected to risk bearing, market coordination, technology diffusion, innovation etc., and we demonstrate they are legally relevant as related to freedom of trade and commerce and competition law principles. In the third chapter, we describe the relevant facts of the "Actium" case, and analyze the legal consequences of using the concept of entrepreneurship to the case, especially to the meaning of the equality principle in this context. Finally, the work concludes that the concept of entrepreneurship is legally relevant, and its use may generate impact to the debate on the level of normative regulatory concentration applicable to the providing of a certain telecommunications service.
\end{abstract}

Keywords: Law. Regulation. Telecommunications. Entrepreneurship. Actium. 


\section{SUMÁRIO}

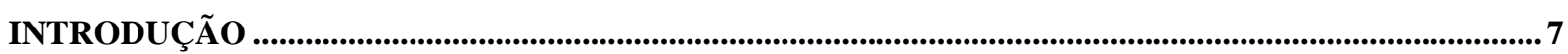

1. REGULAÇÃo JURÍdiCA E O CONCEITO DE GRADAÇÃo DA CONCENTRAÇÃo

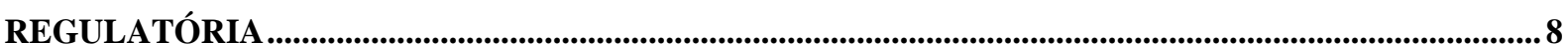

2. EMPREENDEDORISMO: ELEMENTOS FUNCIONAIS DO FENÔMENO E SEU APOIO

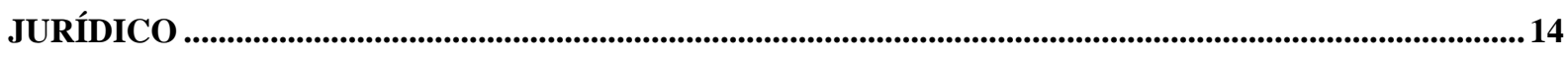

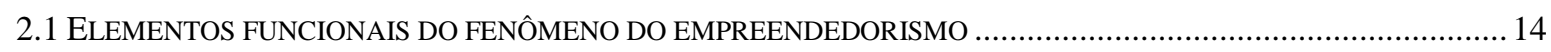

2.2 EMPREENDEDORISMO: APOIO JURÍDICO E SIGNIFICADO INSTITUCIONAL DA LIBERDADE ................................2

3. POSSIBILIDADE DE APLICAÇÃO DO CONCEITO DE EMPREENDEDORISMO: O CASO

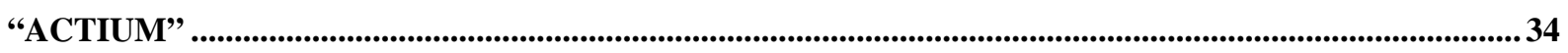

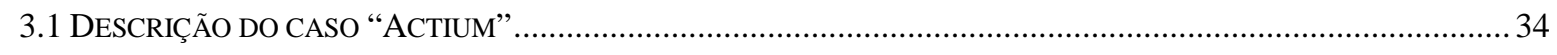

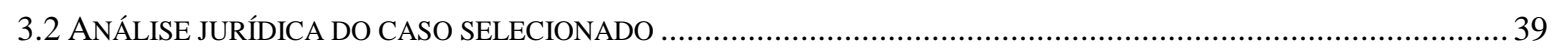

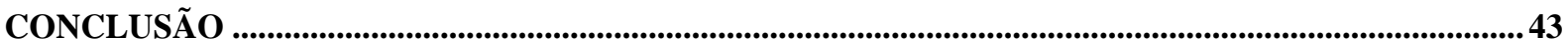

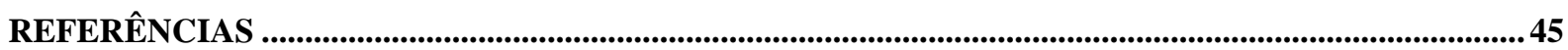




\section{Introdução}

A motivação para este trabalho é a intuição a respeito da capacidade do Direito de interferir nas condições institucionais que propiciam ou dificultam o desenvolvimento do país. Entre os elementos do desenvolvimento, foi escolhido o espírito empreendedor, por sua relação com a valorização do indivíduo e sua liberdade ${ }^{1}$.

Assim, o objetivo do trabalho é entender a relação entre a regulação jurídica e o conceito de empreendedorismo, avaliando a possibilidade e relevância jurídica de sua aplicação em um caso do setor de telecomunicações. Para tanto, foi selecionado o caso "Actium", que diz respeito a um pedido de outorga de autorização para prestação em caráter secundário do serviço de telecomunicações denominado Serviço Móvel Especializado (“SME”), em faixa originariamente destinada ao Serviço Móvel Pessoal (“SMP”). No caso, a Agência Nacional de Telecomunicações (“Anatel”) indeferiu o pedido, por ausência de previsão regulatória. O trabalho discute o fundamento da decisão da Anatel levando em consideração a relação possível entre a regulação jurídica e o conceito de empreendedorismo.

No primeiro capítulo, será abordado o conceito de regulação jurídica a partir da noção de gradação da concentração regulatória, exposta por Herren Aguillar. A noção de gradação da concentração regulatória permite identificar a atuação do Estado com um espectro de possibilidades que mitiga a oposição estanque entre tutela estatal e ausência do Estado, e assim localizar a desconcentração regulatória como uma opção de regulação. A nossa hipótese é que o conceito de empreendedorismo é juridicamente relevante, e assim pode ser cogitado como critério de decisão do grau de concentração regulatória aplicável a determinada atividade.

Em seguida, abordaremos o conceito de empreendedorismo. Reconhecendo-se o caráter interdisciplinar do conceito, será destacado o aspecto funcional para guiar a análise dos seus elementos constitutivos. É a partir desses elementos que sua relevância jurídica pode ser considerada, como dimensões do significado de normas presentes no ordenamento.

No terceiro capítulo, a pesquisa se volta à possibilidade de aplicação do conceito de empreendedorismo ao caso referido. Ao final, a pesquisa pretende confirmar eventual relação entre a regulação jurídica e o conceito de empreendedorismo, avaliando se sua aplicação interfere na argumentação do caso escolhido.

\footnotetext{
${ }^{1}$ Este é o conceito de liberdade referido aqui: “(...) freedom, seen in the form of individual capabilities to do things that a person has reason to value”. SEN, Amartya. Development as freedom. New York: Anchor Books, 1999. p. 56.
} 


\section{Regulação jurídica e o conceito de gradação da concentração regulatória}

O objetivo deste capítulo é demonstrar que a regulação jurídica significa tanto interferência estatal quanto abertura de espaços normativos, em que a conformação do setor de telecomunicações depende de opções dos atores envolvidos. Ao se abrir o referido espaço, o problema que se enfrenta é o de se detectar guias normativos que justifiquem a ausência de normatização expressa para o setor regulado. A importância dessa abordagem para o presente estudo está em que o conceito jurídico de empreendedorismo pode ser cogitado como um dos guias normativos capazes de dimensionar o grau de interferência estatal no setor regulado, bem como interferir na definição da interpretação adequada do sistema regulatório em vigor.

A regulação jurídica é considerada por Herren Aguillar como uma política pública de atribuição de prerrogativas aos agentes de um setor, sejam eles privados ou estatais:

Em outras palavras, neste estudo a regulação jurídica é vislumbrada em sentido amplo, abarcando as diversas formas de atribuição jurídica de prerrogativas aos diversos agentes sociais, sejam eles privados ou estatais. ${ }^{2}$

Estas prerrogativas podem ter caráter tanto de atribuição positiva de funções e obrigações quanto de reserva de espaços de liberdade de atuação, que correspondem a visões de mundo com ênfase reguladora ou desreguladora, respectivamente. Segundo Sundfeld, essas visões de mundo seriam irreconciliáveis ${ }^{3}$. Essa oposição entre visões reflete uma percepção binária das possibilidades de atuação estatal, em que a opção pela regulação é supostamente fruto da preocupação do Estado sobre um determinado setor de atividades; enquanto, em tese, a desregulação é reflexo da entrega de uma atividade aos agentes econômicos, à parte da ação estatal.

A oposição entre regulação e desregulação pode ser mitigada por meio do conceito de gradação da concentração regulatória. Herren Aguillar utiliza este conceito para afirmar que, ao invés de uma oposição entre pólos bem definidos, há um espectro de possibilidades de proporção entre o papel do Estado e da iniciativa privada - proporção esta sempre mediada por uma escolha estatal, conforme explicado a seguir:

\footnotetext{
${ }^{2}$ HERREN AGUILLAR, Fernando. Controle social de serviços públicos. São Paulo: M. Limonad, 1999. p. 29-30.

${ }^{3}$ Segundo Carlos Ari Sundfeld, haveria uma oposição entre visões irreconciliáveis de regulação de serviços públicos, que nomeamos de visão reguladora, ou estatista, e desreguladora, ou liberal: "Para além dos aspectos mais pontuais da controvérsia sobre a validade ou não do novo conceito de serviço público da LGT, há sim uma oposição irreconciliável de visões sobre regulação. Os arautos do serviço público fechado como modelo único crêem que os poderes do regulador devem ser sempre totais e fracos os direitos dos regulados. Já os que admitem no serviço público o sistema de regulações assimétricas entendem necessária a gradação daqueles poderes e direitos, conforme a classe de prestadores e os interesses públicos realmente envolvidos. A primeira visão mais estatista, a segunda mais liberal'. SUNDFELD, Carlos Ari. Meu depoimento e avaliação sobre a Lei Geral de Telecomunicações. Revista de Direito de Informática e Telecomunicações, v. 02, 2007. p. 65 .
} 
O recurso ao conceito de gradação regulatória é capaz de oferecer um instrumento analítico ao papel relativo do Estado e da iniciativa privada nas atividades econômicas. Entendemos aqui que toda liberdade de empreender de que desfrute a iniciativa privada em relação ao Estado é, conquanto paradoxalmente, conseqüência de uma política regulatória estatal, uma política de regulação pela desconcentração. ${ }^{4}$

Não é o Estado que deixa de regular determinada atividade, ou forma de prestação da mesma. Mas, sim, adota política regulatória que define espaços de liberdade nos quais a iniciativa privada atue:

Observamos que a preferência pela expressão "regulação desconcentrada" em detrimento da expressão consagrada desregulamentação se prende a que entendemos que a ausência de regulamentação é uma forma de regulação imposta pelo Estado. ${ }^{5}$

Os espaços de liberdade a que nos referimos podem ser caracterizados ou pela liberdade de atuar diretamente na prestação do serviço, ou pela liberdade de definir as regras sob as quais o serviço é prestado. Essa caracterização dos espaços de liberdade corresponde à natureza operacional ${ }^{6}$ ou normativa ${ }^{7}$, respectivamente, da concentração regulatória que os define. Estas categorias são assim detalhadas por Herren Aguillar:

Concentração regulatória normativa diz respeito à responsabilidade maior ou menor que assuma o Estado na imposição de normas jurídicas aos particulares no desempenho de atividades econômicas. Um determinado setor de atividades que seja regido por normas gerais impositivas de certos comportamentos (intervenção por direção) revela um grau maior de concentração regulatória de tipo normativo, ao passo que atividades econômicas em que a liberdade de contratar é maior, são exemplos de reduzido grau de concentração regulatória normativa.

\section{$(\ldots)$}

Por concentração regulatória operacional entendemos aqui a intensidade com que o Estado avoca a si e a suas entidades a tarefa de desempenhar tarefas econômicas. Grande desconcentração regulatória operacional significa baixa propensão estatal de atuar como agente econômico (intervenção por participação ou absorção), confiando à iniciativa privada a tarefa de empreender e produzir aquilo de que necessita a sociedade. Ao contrário, quando o Estado toma em suas mãos a tarefa empresarial, tende a concentrar a regulação operacional. ${ }^{8}$

Segundo o autor, a análise sistemática da Constituição Federal demonstra que a regra constitucional é a desconcentração regulatória operacional, visto que o Estado apenas exerce atividade econômica diretamente na medida em que há autorização da Constituição Federal

\footnotetext{
${ }^{4}$ HERREN AGUILLAR, Fernando. Controle social de serviços públicos. São Paulo: M. Limonad, 1999. p. 211.

${ }^{5}$ HERREN AGUILLAR, Fernando. Controle social de serviços públicos. São Paulo: M. Limonad, 1999. p. 165.

${ }^{6}$ Sobre o conceito de regulação operacional: "A regulação operacional é manifestada pela preferência outorgada à iniciativa privada ou às empresas e órgãos estaduais para o desempenho de certas atividades de interesse público". HERREN AGUILLAR, Fernando. Controle social de serviços públicos. São Paulo: M. Limonad, 1999. p. 164.

${ }^{7}$ Sobre o conceito de regulação normativa: "Já a regulação normativa diz respeito ao poder de regulamentar efetivamente o setor que interesse ao Estado". HERREN AGUILLAR, Fernando. Controle social de serviços públicos. São Paulo: M. Limonad, 1999. p. 164.

${ }^{8}$ HERREN AGUILLAR, Fernando. Controle social de serviços públicos. São Paulo: M. Limonad, 1999. p. $211-212$.
} 
ou de lei que atenda aos requisitos do art. 173 da Constituição ${ }^{9}$. Por outro lado, o Estado é responsável pela adequação e efetividade dos serviços públicos - mas não necessariamente por sua prestação ao usuário, atividade que é parte de um contexto maior de implementação do serviço ${ }^{10}$. Conforme a Constituição dispõe, a prestação pode ser delegada pelo Estado a particulares ${ }^{11}$.

Entretanto, em princípio, não pode ser uma delegação livre de referências normativas, dado que o interesse privado não necessariamente se orienta pelo interesse público:

Essa delegação [da prestação de serviços públicos a particulares] não pode, porém, ser feita de qualquer forma, visto que não há convergência necessária entre o interesse do particular que explora o serviço público e o interesse (constitucionalmente constituído e a cujo respeito o governante não pode se furtar) de assegurar a satisfação dos seus usuários.

Por isso, a contrapartida necessária da desconcentração regulatória operacional em matéria de serviços públicos é a concentração regulatória normativa, o controle estatal, por exigência constitucional. Ou seja, para que seja possível a outorga da prestação dos serviços públicos aos particulares, se faz necessária a existência de regulação normativa. ${ }^{12}$

Assim, o fundamento da relação entre a diminuição da concentração regulatória operacional e o aumento da concentração regulatória normativa, em um ambiente de delegação estatal da prestação de serviços públicos, é a garantia da prevalência do interesse público, se a ele se opuser o interesse privado. O autor reforça que a satisfação do interesse público pela iniciativa privada serve de guia para a confiança do Estado, que repercute no grau de concentração regulatória (tanto operacional quanto normativa):

O grau de concentração regulatória revela a confiança maior ou menor do Estado em que os interesses públicos serão alcançados mediante outorga de liberdade à iniciativa privada. A ampla liberdade de iniciativa (controle pela desconcentração) revela que os fins do Estado, na opinião do próprio Estado, podem ser alcançados plenamente pela ação dos particulares. Já o controle pela concentração denota uma relativa falta de confiança em que a iniciativa privada possa espontaneamente alcançar os fins patrocinados pelo Estado. ${ }^{13}$ (grifo nosso)

Herren Aguillar bem identifica o interesse público como fundamento e medida determinante do grau de concentração da regulação normativa ${ }^{14}$, mas naturaliza a oposição do interesse privado ao interesse público, transformando-a em pressuposto: daí assumir uma

\footnotetext{
${ }^{9}$ HERREN AGUILlAR, Fernando. Controle social de serviços públicos. São Paulo: M. Limonad, 1999. p. 212.

${ }^{10}$ HERREN AGUILLAR, Fernando. Controle social de serviços públicos. São Paulo: M. Limonad, 1999. p. 213.

${ }^{11}$ No caso dos serviços de telecomunicações, o dispositivo pertinente da Constituição é o art. 21, XI: "Art. 21. Compete à União: XI explorar, diretamente ou mediante autorização, concessão ou permissão, os serviços de telecomunicações, nos termos da lei, que disporá sobre a organização dos serviços, a criação de um órgão regulador e outros aspectos institucionais;".

${ }^{12}$ HERREN AGUILLAR, Fernando. Controle social de serviços públicos. São Paulo: M. Limonad, 1999. p. 213.

${ }^{13}$ HERREN AGUILLAR, Fernando. Controle social de serviços públicos. São Paulo: M. Limonad, 1999. p. 164.

${ }^{14}$ Isto fica claro no seguinte trecho: “(...) o interesse público é sempre determinante do perfil regulatório dos serviços públicos. É o interesse público que determina o grau de concentração regulatória (...)”. HERREN AGUILLAR, Fernando. Controle social de serviços públicos. São Paulo: M. Limonad, 1999. p. 163.
} 
necessidade, em sentido determinista, de compensação da desconcentração regulatória operacional pela concentração regulatória normativa. Neste trabalho, entende-se que o interesse público, como fundamento que é da normatização, deva ser exposto ${ }^{15}$, pesado, medido, questionado, interferindo potencialmente no grau de concentração regulatória correspondente a cada aplicação ${ }^{16}$.

O interesse público, para Celso Antonio Bandeira de Mello, pode assumir as facetas de interesse primário ou secundário:

Interesse público ou primário é o pertinente à sociedade como um todo e só ele pode ser validamente objetivado, pois este é o interesse que a lei consagra e entrega à compita do Estado como representante do corpo social. Interesse secundário é aquele que atina tão-só ao aparelho estatal enquanto entidade personalizada e que por isso mesmo pode lhe ser referido e nele encarnar-se pelo simples fato de ser pessoa.

\section{(...)}

Para exemplificar o importante discrímen entre um e outro, comparem-se as seguintes hipóteses. Se o Estado causar danos a terceiros e indenizá-los das lesões inflingidas estará revelando-se obsequioso ao interesse público, pois isto é o que determina o art. $37, \S 6^{\circ}$, da Constituição. Se tentar evadir-se a este dever de indenizar (mesmo consciente de haver produzido os danos) estará contrariando o interesse público, no afã de buscar um interesse secundário, concernente apenas ao aparelho estatal: interesse em subtrair-se a despesas (conquanto devidas) para permanecer mais "rico", menos onerado patrimonialmente, lançando, dessarte, sobre ombros alheios os ônus que o Direito pretende sejam suportados por todos. Tal conduta não é de interesse público, pois interesses secundários só podem ser satisfeitos quando coincidirem com interesses primários. ${ }^{17}$

A classificação de Celso Antonio Bandeira de Mello é relevante por destacar que o critério determinante para a ação estatal baseada no interesse público é a lei ${ }^{18}$, enquanto concretização dos interesses e valores dos agentes sociais. Conforme o autor, o interesse do Estado, enquanto ente personalizado, é secundário e deve ser prestigiado apenas na medida em que coincide com o interesse público primário. Em outras palavras, o grau de liberdade que será conferido ao Estado e à iniciativa privada deve levar em conta os valores, interesses e objetivos dispostos em lei - é isto que define o regime jurídico aplicável a um setor de atividades.

Neste ponto, enfrenta-se o problema de que os valores, objetivos e interesses dispostos na normatização, que dão concretude ao interesse público, podem não ser

\footnotetext{
${ }^{15}$ Conforme o princípio da motivação dos atos administrativos e o dever de observância do interesse público, com suporte normativo no art. $2^{\circ}$ da Lei $n^{\circ} 9.784$, de 29 de janeiro de 1999.

${ }^{16}$ Isto significa que pode haver graus de concentração regulatória operacional ou normativa com abrangência variada. Herren Aguillar classifica os tipos de regulação por áreas de abrangência, por assim dizer, em: regulação setorial, regional e geral. HERREN AGUILLAR, Fernando. Controle social de serviços públicos. São Paulo: M. Limonad, 1999. p. 214. A depender do tipo de regulação com que se esteja lidando, a interferência do interesse público no grau de concentração regulatória terá maior ou menor repercussão no regime jurídico de um determinado setor de atividades, região territorial ou em todo o país.

${ }^{17}$ MELLO, Celso Antonio Bandeira de. Elementos de direito administrativo. São Paulo: Ed. RT, 1991. p. 54.

${ }^{18}$ Conforme: "Com efeito, dita qualificação [de interesse público] quem a faz é a Constituição e, a partir dela, o Estado, primeiramente através dos órgãos legislativos, e depois por via dos órgãos administrativos, nos casos e limites da discricionariedade que a lei lhes haja conferido". MELLO, Celso Antonio Bandeira de. Curso de Direito Administrativo. São Paulo: Malheiros, 2003. p. 59.
} 
uniformes. Podem ser destacados dois aspectos da referida heterogeneidade.

Em primeiro lugar, a complexidade da atuação estatal torna o âmbito de aplicação de cada conjunto normativo restrito, com características próprias. Prevalece a regulação setorial, compartimentada por setor de atividade relevante, ou regional, por espaço territorial, em detrimento da regulação geral ${ }^{19}$. Entre os grandes temas de atuação estatal, há a regulamentação de telecomunicações, petróleo, saúde etc., cada uma com seus princípios de atuação próprios. Segundo, pode haver diversidade de valores e interesses dentro dos próprios setores anteriormente mencionados. Carlos Ari Sundfeld expõe a complexidade interna das telecomunicações da seguinte maneira:

As telecomunicações são um complexo de situações reguladas, cada uma a seu modo.

\section{(...)}

O tratamento regulatório das várias situações - isto é, das classes de prestadores ou serviços - é específico, na medida da justificativa que exista para regular e dos objetivos que se possa legitimamente buscar em cada caso. É o fenômeno da assimetria regulatória. Eis, então, a nova formulação: os serviços de telecomunicações são sujeitos a um sistema de regulações públicas assimétricas. ${ }^{20}$

Por sua vez, Floriano Peixoto de Azevedo Marques Neto, radicaliza a ideia de complexidade da definição de interesse público, e afirma a necessidade de tradução do interesse público para o caso concreto, não só para classes de prestadores ou serviços:

Ora, a idéia de que o interesse público seria aquele prescrito na lei acarretava, necessariamente, a idéia de existência de um - e apenas um - interesse público primário. Porém, ocorre que - conforme leciona Alessandro Pizzorusso - "o que se encontra na vida real são os múltiplos e diversos interesses públicos, enquanto o interesse público no singular é apenas uma locutio brevis para indicar qual o interesse público em si dentre aqueles que será aquele que deva ser consagrado no caso concreto". ${ }^{21}$

Para o autor, do ponto de vista estrutural, o interesse público é definido como "elo de mediação de interesses privados dotados de legitimidade" ${ }^{, 22}$. Isto não significa que quaisquer interesses possam fazer parte desse processo. Na tipologia de interesses passíveis de mediação pelo Estado que é proposta pelo autor, os interesses podem ser tanto especiais quanto difusos. Em todo caso, a legitimidade dos interesses em jogo é avaliada tanto factual quanto juridicamente, conforme dispõe o trecho abaixo ${ }^{23}$ :

\footnotetext{
${ }^{19}$ Conforme já dito acima, a classificação da regulação em setorial, regional e geral está em: HERREN AGUILLAR, Fernando. Controle social de serviços públicos. São Paulo: M. Limonad, 1999. p. 214.

${ }^{20}$ SUNDFELD, Carlos Ari. Meu depoimento e avaliação sobre a Lei Geral de Telecomunicações. Revista de Direito de Informática e Telecomunicações, v. 02, 2007. p. 64.

${ }^{21}$ MARQUES NETO, Floriano Peixoto de Azevedo. Regulação estatal e interesses públicos. São Paulo: Malheiros, 2002. p. 156.

22 MARQUES NETO, Floriano Peixoto de Azevedo. Regulação estatal e interesses públicos. São Paulo: Malheiros, 2002. p. 149.

${ }^{23}$ MARQUES NETO, Floriano Peixoto de Azevedo. Regulação estatal e interesses públicos. São Paulo: Malheiros, 2002. p. 161-162.
} 
Os interesses especiais, na medida em que se revelem legitimados perante uma parcela da sociedade e encontrem eco nos princípios estruturantes do ordenamento jurídico, não podem ser desconsiderados como interesse público. A partir do momento em que se revelem transcendentes aos interesses particularísticos dos atores sociais organizados, que os encampam, tais interesses passam a ser interesses públicos consideráveis, devendo ser tomados em conta no processo decisório voltado à alocação de bens, direitos e oportunidades amealhados pela coletividade. Neste particular, a Administração Pública se revela necessária na mediação entre os interesses especiais.

Será, porém, nos interesses difusos que mais relevante se põe o exercício do poder político. Efetivamente, na tutela desta classe de interesses públicos é que reside a principal razão de ser do poder político numa perspectiva hodierna. A principal parcela de interesses públicos que demanda a atuação efetiva do poder político cinge-se à tutela dos interesses difusos dotados de hipossuficiência.

Assim, se o interesse público é o critério que define o grau de concentração regulatória normativa, não é um critério uniforme, nem para todos os setores regulados, nem dentro dos próprios setores ${ }^{24}$. Naturalmente isto gerará diferentes graus de concentração regulatória. Além disso, pode-se radicalizar a assunção da complexidade do interesse público, admitindo sua definição no caso concreto. Isto ocorre em um processo de mediação de interesses, todos legitimados factual e juridicamente, ou seja, fundamentados em demandas sociais e em princípios do ordenamento jurídico. Em última análise, a definição do grau de concentração regulatória em um dado caso deve levar em conta todos os interesses que cumpram os requisitos acima.

A partir deste quadro, a abertura de espaço normativo para a prestação de serviços públicos pela iniciativa privada pode ser justificada pela consideração estatal de um interesse fundado em um conceito juridicamente relevante ${ }^{25}$, em jogo com outros interesses. É assim que a abordagem do conceito jurídico de empreendedorismo se faz importante como argumento para a justificação de relativa desconcentração regulatória normativa na regulação de determinada atividade. Caso esta justificação se confirme em abstrato, poderemos proceder à sua avaliação em face de um caso concreto, e verificar se o referido conceito produz efeitos juridicamente relevantes na interpretação da regulamentação em vigor.

\footnotetext{
${ }^{24}$ Ainda segundo Floriano Peixoto de Azevedo Marques Neto: "Decorre daí a noção de que a homogeneidade do interesse público tem que dar lugar à idéia de heterogeneidade de interesses públicos. Nas palavras de Giannini, 'hoje a realidade nos mostra que também os interesses da esfera pública são heterogêneos"'. MARQUES NETO, Floriano Peixoto de Azevedo. Regulação estatal e interesses públicos. São Paulo: Malheiros, 2002. p. 151.

${ }^{25}$ A demanda social como critério de legitimidade é sempre aferida no caso concreto, e pode ser dada como existente sempre que a resposta estatal se der mediante provocação pelo particular, dado que a provocação do Estado é a própria manifestação da demanda social.
} 


\section{Empreendedorismo: elementos funcionais do fenômeno e seu apoio jurídico}

Busca-se, neste capítulo, demonstrar que o conceito de empreendedorismo é juridicamente relevante, identificando-se o seu locus normativo no ordenamento jurídico brasileiro. Para tanto, será feito um apanhado da literatura que define os elementos do fenômeno do empreendedorismo, a partir dos quais serão identificados os respectivos pontos de apoio no ordenamento jurídico. A exposição leva esse objetivo em conta, o que lhe dá o perfil de um panorama voltado a sistematizar os elementos centrais das correntes de pensamento.

\subsection{Elementos funcionais do fenômeno do empreendedorismo}

As definições de empreendedorismo são muito variadas na literatura ${ }^{26}$. Michael Peneder indica dois fatores que influenciam isto ${ }^{27}$. O primeiro fator consiste em não haver consenso sobre as funções essenciais que são imputadas ao empreendedorismo. Segundo o autor acima citado, a literatura sugere que o fenômeno é responsável ao mesmo tempo tanto pelo movimento do sistema econômico em direção ao equilíbrio como pela geração de desequilíbrio no mercado. Isto é, a depender da corrente intelectual, o empreendedorismo é fator que aumenta a eficiência alocativa para dados meios e fins, ou dinamiza a atividade econômica pela criação progressiva de novos produtos, serviços, processos ou mercados ${ }^{28}$.

Em segundo lugar, a variedade de conceitos se deve à natureza interdisciplinar do tema, envolvendo estudiosos dos campos de economia, administração, sociologia e psicologia, não raro com linhas divergentes em cada um desses campos ${ }^{29}$. Em cada área, há uma tendência de o conceito de empreendedorismo refletir o aspecto do fenômeno que é mais caro aos interesses de estudo próprios da área. Como Peneder explica, o economista em geral está preocupado em entender o funcionamento do sistema econômico e, por isso, tem a

\footnotetext{
${ }^{26}$ HÉBERT, Robert F.; LINK, Albert N. In the search of the meaning of entrepreneurship. In: Small Business Economics. Vol. 1 No 1. Norwell: Kluwer Academic Publishers, 1989. p. 41.

${ }^{27}$ PENEDER, Michael R. The Meaning of Entrepreneurship: Towards a Modular Concept. WIFO Working Papers, No. 335. Viena: WIFO, Março de 2009. p. 2. Disponível em: http://www.wifo.ac.at/wwa/servlet/wwa.upload.DownloadServlet/bdoc/WP_2009_335\$.PDF. Acesso em: 26/11/09.

${ }^{28}$ PENEDER, Michael R. The Meaning of Entrepreneurship: Towards a Modular Concept. WIFO Working Papers, No. 335. Viena: WIFO, Março de 2009. p. 2. Disponível em: http://www.wifo.ac.at/wwa/servlet/wwa.upload.DownloadServlet/bdoc/WP_2009_335\$.PDF. Acesso em: 26/11/09.

${ }^{29}$ PENEDER, Michael R. The Meaning of Entrepreneurship: Towards a Modular Concept. WIFO Working Papers, No. 335. Viena: WIFO, Março de 2009. p. 2. Disponível em: http://www.wifo.ac.at/wwa/servlet/wwa.upload.DownloadServlet/bdoc/WP 2009 335\$.PDF. Acesso em: $26 / 11 / 09$.
} 
tendência de caracterizar o empreendedorismo pelas funções particulares que exerce no desenvolvimento da economia. Entre os economistas, há aqueles que estudam a escolha ocupacional, entre ser um assalariado e um autônomo - este considerado o empreendedor. Administradores dão ênfase ao aspecto comportamental, interessados em como agir de maneira empreendedora ${ }^{30}$, enquanto sociólogos se voltam para a explicação da influência social no comportamento empreendedor. Já o psicólogo quer entender como o empreendedorismo se relaciona com características pessoais e processos cognitivos dos indivíduos, dentro de cada contexto situacional. E assim por diante.

Analisando essas diferenças, Peneder identifica três aspectos que estão de uma maneira ou de outra representados nos diversos conceitos: definição comportamental geral, diferenciação funcional e categorias ocupacionais. Essas três dimensões constituem conceitos independentes que, não obstante, permanecem interrelacionados e complementam um ao outro $^{31}$. Seguindo os passos do autor, o foco da análise abaixo é a literatura econômica, que privilegia a dimensão funcional, e pretende explicar o papel do empreendedorismo nas interações do mercado e para o desenvolvimento econômico. $\mathrm{O}$ aspecto funcional do empreendedorismo é privilegiado neste trabalho pois permite alcançar maior capacidade argumentativa quando se trata da proteção jurídica de atividades, sejam elas quais forem.

Sete correntes teóricas merecem destaque ${ }^{32}$. Nelas, a figura do indivíduo empreendedor $^{33}$ exerce a função de: (i) dono de um negócio; (ii) assunção de risco; (iii) coordenação de mercado; (iv) inovação; (v) difusão de tecnologias; (vi) rent-seeking ${ }^{34}$; e (vii)

\footnotetext{
${ }^{30}$ Um dos autores do campo da administração, Peter Drucker, assim define empreendedorismo: “Os empreendedores veem a mudança como a regra e algo que é saudável. Geralmente, eles não produzem a mudança por si mesmos. Mas - e isto define o empreendedor e o empreendedorismo - o empreendedor sempre procura a mudança, responde a ela, e a explora como uma oportunidade". Tradução livre de: "Entrepreneurs see change as the norm and as healthy. Usually, they do not bring about the change themselves. But - and this defines entrepreneur and entrepreneurship - the entrepreneur always searches for change, responds to it, and exploits it as an opportunity". DRUCKER, Peter F. Innovation and entrepreneurship: practice and principles. Oxford: Butterworth-Heinemann, 2007. p. 25.

${ }^{31} \mathrm{O}$ autor oferece a sistematização mais coerente dos conceitos de empreendedorismo da literatura, em seus diversos aspectos. Esse é o motivo pelo qual a referência ao autor é recorrente. PENEDER, Michael R. The Meaning of Entrepreneurship: Towards a Modular Concept. WIFO Working Papers, No. 335. Viena: WIFO, Março de 2009. p. $15 . \quad$ Disponível em: http://www.wifo.ac.at/wwa/servlet/wwa.upload.DownloadServlet/bdoc/WP 2009 335\$.PDF. Acesso em: 26/11/09.

${ }^{32}$ PENEDER, Michael R. The Meaning of Entrepreneurship: Towards a Modular Concept. WIFO Working Papers, No. 335. Viena: WIFO, Março de 2009. p. 4-13. Disponível em: http://www.wifo.ac.at/wwa/servlet/wwa.upload.DownloadServlet/bdoc/WP 2009 335\$.PDF. Acesso em: 26/11/09.

${ }^{33}$ As definições de empreendedorismo vistas aqui são usualmente guiadas pela definição do empreendedor enquanto papel do indivíduo que exerce o empreendedorismo. A título de ilustração: "O empreendedorismo é, assim, uma característica distinta seja de um indivíduo ou de uma instituição". Tradução livre de: "Entrepreneurship is thus a distinct feature whether of and individual or of an institution". DRUCKER, Peter F. Innovation and entrepreneurship: practice and principles. Oxford: Butterworth-Heinemann, 2007. p. 23. Isso não significa que outras opções não sejam possíveis, conforme exemplifica o seguinte conceito, que enfatiza processos de percepção de oportunidades: "O empreendedorismo é uma atividade que envolve a descoberta, avaliação e exploração de oportunidades para introduzir novos produtos e serviços, formas de organização, mercados, processos e matérias-primas por meio da organização de esforços que previamente não existiam (...)". Tradução livre de: "Entrepreneurship is an activity that involves the discovery, evaluation and exploitation of opportunities to introduce new goods and services, ways of organizing, markets, processes, and raw materials through organizing efforts that previously had not existed (...)". SHANE, Scott Andrews. A General Theory of Entrepreneurship: The Individual-Opportunity Nexus (Série "New Horizons in Entrepreneurship"). Cheltenham, UK: Edward Elgar, 2003. p. 4. Entretanto, este trabalho privilegia a abordagem a partir da função do sujeito empreendedor, muito comum na literatura, e adapta os conceitos sempre que possível, em favor da uniformidade metodológica.

${ }^{34} \mathrm{O}$ termo se refere a atividades que desperdiçam recursos praticadas por indivíduos e grupos que buscam transferência de riquezas. Em outras palavras, são atividades não-produtivas que geram riqueza para quem as pratica, em detrimento da sociedade. Conforme: "There is an increasing use of the concept of rent seeking to describe resource-wasting actitivies for individuals and groups seeking wealth transfers".
} 
empreendedor corporativo.

O empreendedor pode ser entendido como o dono de um negócio. Embora na origem o conceito signifique a condução geral de um negócio (general undertaking of a business), o conceito foi depois popularizado por Jean-Baptiste Say como um tipo especial de função que é responsável por combinar os fatores de produção, isto é, a função gerencial ${ }^{35}$. Assim, o empreendedor é um gerente especializado, que coordena o trabalho de outros empregados: “(...) eles [os empreendedores] reúnem o capital e o trabalho necessários para a produção; eles organizam ou 'desenham' seu planejamento geral, e supervisionam seus mínimos detalhes"36. Simultaneamente, o próprio empreendedor serve de empregado ao capitalista, que detém o capital que o financia. Assim, a ligação entre o empreendedorismo e a gestão de negócios para essa corrente é clara. A definição de Mark Casson se alinha em grande medida com essa corrente: para o autor, o empreendedor é alguém especialista na tomada de decisões valorativas sobre a coordenação de recursos escassos ${ }^{37}$. Essa ideia é coerente com a teoria neoclássica da produção: o empreendedor gerencia e otimiza a alocação de recursos, e maximiza a eficiência do agregado $^{38}$. Entretanto, a atribuição ao empreendedor da função gerencial pura, de monitoramento e supervisão, não é bem recebida entre os economistas em geral $^{39}$.

Outros autores ressaltam que a característica própria da atividade empreendedora é a assunção de risco, ou de incerteza ${ }^{40}$, a exemplo de Cantillon ${ }^{41}$. Cantillon identifica que certos agentes contratam fornecedores e trabalhadores a um preço determinado para fabricar produtos que serão vendidos a um preço incerto ${ }^{42}$. Essa incerteza que o empreendedor assume seria o fundamento do seu lucro. Frank Knight, em reforço a essa teoria, relata o surgimento

PASOUR, JR., E. C. Rent Seeking: Some Conceptual Problems and Implications. In: The Review of Austrian Economics. Vol. 1 No. 1. Fairfax County, Virginia: Kluwer Academic Publishers, 1987. p. 123. Disponível em: http://mises.org/journals/rae/pdf/rae1_1_8.pdf. Acesso em: $30 / 11 / 09$.

${ }^{35}$ PENEDER, Michael R. The Meaning of Entrepreneurship: Towards a Modular Concept. WIFO Working Papers, No. 335. Viena: WIFO, Março de 2009. p. 5. Disponível em: http://www.wifo.ac.at/wwa/servlet/wwa.upload.DownloadServlet/bdoc/WP 2009 335\$.PDF. Acesso em: 26/11/09.

${ }^{36}$ Tradução livre de: “(...) they bring together the capital and the labour required for the work; they arrange or 'engineer' its general plan, and superintend its minor details.” MARSHALL, Alfred. Principles of Economics: unabridged eigth edition. Nova York: Cosimo, 2009. p. 244.

${ }^{37}$ Conforme: “(...) an entrepreneur is someone who specializes in taking judgmental decisions about the coordination of scarce resources." CASSON, Mark. The entrepreneur: an economic theory. 2a ed. Cheltenham, UK: Edward Elgar Publishing, 2003. p. 20.

${ }^{38}$ PENEDER, Michael R. The Meaning of Entrepreneurship: Towards a Modular Concept. WIFO Working Papers, No. 335. Viena: WIFO, Março de 2009. p. 6. Disponível em: http://www.wifo.ac.at/wwa/servlet/wwa.upload.DownloadServlet/bdoc/WP_2009_335\$.PDF. Acesso em: 26/11/09.

${ }^{39}$ PENEDER, Michael R. The Meaning of Entrepreneurship: Towards a Modular Concept. WIFO Working Papers, No. 335. Viena: WIFO, Março de 2009. p. 6. Disponível em: http://www.wifo.ac.at/wwa/servlet/wwa.upload.DownloadServlet/bdoc/WP_2009_335\$.PDF. Acesso em: $26 / 11 / 09$.

${ }^{40}$ PENEDER, Michael R. The Meaning of Entrepreneurship: Towards a Modular Concept. WIFO Working Papers, No. 335. Viena: WIFO, Março de 2009. p. 6. Disponível em: http://www.wifo.ac.at/wwa/servlet/wwa.upload.DownloadServlet/bdoc/WP 2009 335\$.PDF. Acesso em: 26/11/09.

${ }^{41}$ CANTILLON, Richard. Essays on the nature of commerce in general. Nova introdução por Antony Brewer. New Brunswick, New Jersey: Transaction Publishers, 2001. p. 24.

${ }^{42}$ CANTILLON, Richard. Essays on the nature of commerce in general. Nova introdução por Antony Brewer. New Brunswick, New Jersey: Transaction Publishers, 2001. p. 25. 
do papel do empreendedor no processo de especialização que é próprio da organização empresarial. Nesse processo de especialização, os chamados empreendedores assumem o controle e a responsabilidade pelo processo produtivo e arcam com o risco intrínseco à atividade, enquanto os empregados se inserem na produção sem arcar com o risco pelo resultado. Knight assim descreve que suportar o risco do empreendimento é o caráter distintivo do empreendedor:

\begin{abstract}
A essência da empresa é a especialização da função de direção responsável da vida econômica, cuja característica negligenciada é a inseparabilidade destes dois elementos, responsabilidade e controle. No sistema empresarial, uma classe social especial, os homens de negócios, dirige a atividade econômica; eles são produtores em sentido estrito, enquanto a grande massa da população meramente os provê com serviços de produção, colocando sua pessoa e propriedade à disposição dessa classe; o empreendedor também garante àqueles que provêem serviços de produção uma remuneração fixa. Definir precisamente essas funções e rastreá-las através da estrutura social será uma longa tarefa, dado que a especialização nunca é completa; mas ao final dela nós devemos concluir que em uma sociedade livre as duas são essencialmente inseparáveis. Qualquer grau de exercício efetivo de juízo, ou tomada de decisões, é em uma sociedade livre acompanhado de um correspondente grau de assunção de incerteza, de aceitação da responsabilidade por tais decisões. ${ }^{43}$
\end{abstract}

A função de assunção do risco leva a questionamentos de natureza ocupacional, ou seja, de escolha da atividade que se quer realizar. O empreendedorismo é explicado como um resultado conjugado do que são essencialmente as funções do capitalista e do gerente, unidas em um típico dono do próprio negócio. Isto costuma ocorrer em pequenas e médias empresas, já que em grandes corporações é regra a separação entre a propriedade (assunção de risco) e o controle (gerenciamento do negócio) ${ }^{44}$.

A terceira abordagem é aquela que valoriza o empreendedorismo como processo de coordenação de mercado. Isto é, como o processo de identificação de oportunidades lucrativas no mercado. Hayek, em especial, explicou que o processo competitivo estimula a descoberta de oportunidades de lucro através da informação revelada no movimento do sistema de preços:

Fundamentalmente, em um sistema em que o conhecimento dos fatos relevantes está disperso entre muitas pessoas, os preços podem agir para coordenar as ações separadas das

\footnotetext{
${ }^{43}$ Tradução livre de: "The essence of enterprise is the specialization of the function of responsible direction of economic life, the neglected feature of which is the inseparability of these two elements, responsibility and control. Under the enterprise system, a special social class, the business men, direct economic activity; they are in the strict sense the producers, while the great mass of the population merely furnish them with productive services, placing their persons and their property at the disposal of this class; the entrepreneurs also guarantee to those who furnish productive services a fixed remuneration. Accurately to define these functions and trace them through the social structure will be a long task, for the specialization is never complete; but at the end of it we shall find that in a free society the two are essentially inseparable. Any degree of effective exercise of judgment, or making decisions, is in a free society coupled with a corresponding degree of uncertaintybearing, of taking the responsibility for those decisions”. KNIGHT, Frank Hyneman. Risk, Uncertainty and Profit. Nova York, NY: Cosimo, 2005. p. 271

${ }^{44}$ PENEDER, Michael R. The Meaning of Entrepreneurship: Towards a Modular Concept. WIFO Working Papers, No. 335. Viena: WIFO, Março de 2009. p. 6. Disponível em: http://www.wifo.ac.at/wwa/servlet/wwa.upload.DownloadServlet/bdoc/WP 2009 335\$.PDF. Acesso em: 26/11/09.
} 
diferentes pessoas, do mesmo modo que valores subjetivos ajudam os indivíduos a coordenar as partes de seu planejamento. ${ }^{45}$

Também destacando o processo de identificação de oportunidades, Kirzner caracteriza o empreendedor como um intermediário, alerta às oportunidades de acoplar custos baixos, do lado dos fornecedores, a receitas altas, do lado dos clientes:

O empreendedor puro, por outro lado, utiliza seu senso de alerta para descobrir e explorar situações em que ele é capaz de vender por preços altos aquilo que ele pode comprar por preços baixos. O lucro do empreendedorismo puro é a diferença entre os dois níveis de preços. Não é ganho pela troca de algo que o empreendedor valoriza menos por algo que ele valoriza mais. Vem da descoberta de vendedores e compradores de algo pelo qual os últimos irão pagar mais do que [o valor que] os primeiros cobram. ${ }^{46}$

Nas palavras de Michael Peneder, a respeito da função de coordenação de mercado do empreendedor:

A resposta empreendedora pode ser uma de duas: intermediação em relações comerciais puras ou o ajuste da produção a mudanças nos preços de insumos e/ou tecnologia. Em ambos os casos, as oportunidades já estão dadas e as sinalizações de preços no mercado alertam os empreendedores e desencadeiam sua atividade. Em resumo, a busca e exploração de oportunidades lucrativas do empreendedor dirige o processo de coordenação de mercado, com sinalizações de preços no mercado servindo como seus guias. 47

Enquanto a coordenação de mercado enfatiza as oportunidades que estão dadas, o empreendedorismo é considerado por outros autores como motor da inovação. Ao invés de equilíbrio entre oferta e demanda, tendendo a um ponto de máxima eficiência alocativa a partir das oportunidades existentes, há criação de oportunidades, com geração de correspondente instabilidade econômica ${ }^{48}$. Essa instabilidade não é considerada estranha, e sim parte essencial da dinâmica econômica.

Especificamente, Schumpeter identifica como empreendedor o papel do indivíduo que realiza inovações na combinação dos fatores de produção. Nesse sentido, a figura do

\footnotetext{
${ }^{45}$ Tradução livre de: "Fundamentally, in a system in which the knowledge of the relevant facts is dispersed among many people, prices can act to co-ordinate the separate actions of different people in the same way as subjective values help the.individual to co-ordinate the parts of his plan". HAYEK, F.A. The use of knowledge in society. In: American Economic Review. Vol. 35, No. 4. Pittsburg: American Economic Association, Setembro, 1945. p. 526.

${ }^{46}$ Tradução livre de: "The pure entrepreneur, on the other hand, proceed by his alertness to discover and exploit situations in which he is able to sell for high prices that which he can buy for low prices. Pure entrepreneurial profit is the difference between the two sets of prices. It is not yielded by exchanging something the entrepreneur values less for something he values more highly. It comes from discovering sellers and buyers of something for which latter will pay more than the former demand". KIRZNER, Israel M. Competition and Entrepreneurship. Chicago: University of Chicago Press, 1973. p. 48.

${ }_{47}$ Tradução livre de: "The entrepreneurial response can be either of both: arbitrage in pure trading relationships or the adjustment of production to changes in input prices and/or technology. In both cases opportunities are already given and price signals in the market alert the entrepreneurs and trigger their activity. In short, the entrepreneurial pursuit and exploitation of profit opportunities drives the process of market coordination with the price signals on the market being its guideposts". PENEDER, Michael R. The Meaning of Entrepreneurship: Towards a Modular Concept. WIFO Working Papers, No. 335. Viena: WIFO, Março de 2009. p. 8. Disponível em: http://www.wifo.ac.at/wwa/servlet/wwa.upload.DownloadServlet/bdoc/WP_2009_335\$.PDF. Acesso em: 26/11/09.

${ }^{48}$ PENEDER, Michael R. The Meaning of Entrepreneurship: Towards a Modular Concept. WIFO Working Papers, No. 335. Viena: WIFO, Março de 2009. p. 9. Disponível em: http://www.wifo.ac.at/wwa/servlet/wwa.upload.DownloadServlet/bdoc/WP 2009 335\$.PDF. Acesso em: $26 / 11 / 09$.
} 
empreendedor se diferencia do capitalista, que detém os meios de produção e assume os riscos

do empreendimento, e do gerente, que lida com o dia-a-dia do negócio:

A implementação de novas combinações nós chamamos de "empreendimento"; os indivíduos cuja função é implementá-las nós chamamos de "empreendedores." Esses conceitos são a um só tempo mais amplos e mais restritos que o usual. Mais amplos, porque em primeiro lugar nós chamamos empreendedores não apenas aqueles homens de negócios "independentes" em uma economia de trocas que são assim geralmente designados, mas todos que realmente exercem a função pela qual nós definimos o conceito, mesmo se são, como está se tornando a regra, empregados "dependentes" de uma companhia, como gerentes, membros de conselhos de diretores, e assim por diante, ou mesmo que seu poder de fato de exercer a função empreendedora tenha outros fundamentos, tal como o controle da maioria das ações. Como é a implementação de novas combinações o que constitui o empreendedor, não é necessário que ele deva estar permanentemente ligado a uma determinada empresa; muitos "financiadores", "promotores," e assim por diante não são, e ainda assim podem ser empreendedores em nosso sentido. De outro lado, nosso conceito será mais restrito que o tradicional no que ele não inclui todos os diretores de empresas ou gerentes ou industriais que podem meramente operar um negócio estabelecido, mas apenas aqueles que efetivamente exercem esta função [de empreendedores]. Todavia, eu reafirmo que a definição acima não faz mais que formular com maior precisão o que a doutrina tradicional realmente quer transmitir. Em primeiro lugar, nossa definição concorda com a usual no ponto fundamental da distinção entre "empreendedores" e "capitalistas" - independentemente de se os últimos são considerados donos do dinheiro, de crédito monetário ou bens materiais. Essa distinção é senso comum hoje e tem sido assim por um tempo considerável. Também resolve a questão de se o acionista ordinário como tal é um empreendedor, e dispensa a concepção de empreendedor como aquele que assume o risco. ${ }^{49}$

Schumpeter ainda acrescenta a este quadro um quarto papel: o de inventor. O autor esclarece que é insuficiente ter acesso à invenção em si, ou à ideia de uma combinação nova dos fatores de produção. O fundamental é a implementação efetiva da inovação - ainda que seja possível a coincidência de papéis de inventor e empreendedor em uma só pessoa, como também ocorre em relação aos outros papéis ${ }^{50}$. Por sua clareza, é merecedora de citação a sistematização dos papéis mencionados proposta por Erik Stam:

\footnotetext{
${ }^{49}$ Tradução livre de: "The carrying out of new combinations we call 'enterprise'; the individuals whose function is to carry them out we call 'entrepreneurs.' These concepts are at once broader and narrower than usual. Broader, because in the first place we call entrepreneurs not only those 'independent' businessmen in an exchange economy who are usually so designated, but all who actually fulfill the function by which we define the concept, even if they are, as is becoming the rule, 'dependent' employees of a company, like managers, members of boards of directors, and so forth, or even if their actual power to perform the entrepreneurial function has any other foundations, such as the control of a majority of shares. As it is the carrying out of new combinations that constitutes the entrepreneur, it is not necessary that he should be permanently connected with an individual firm; many 'financiers,' 'promoters,' and so forth are not, and still they may be entrepreneurs in our sense. On the other hand, our concept is narrower than the traditional one in that it does not include all heads of firms or managers or industrialists who merely may operate an established business, but only those who actually perform that function. Nevertheless I maintain that the above definition does no more than formulate with greater precision what the traditional doctrine really means to convey. In the first place our definition aggress with the usual one on the fundamental point of distinguishing between 'entrepreneurs' and 'capitalists' irrespective of whether the latter are regarded as owners of money, claims to money, or material goods. This distinction is common property to-day and has been so for a considerable time. It also settles the question whether the ordinary shareholder as such is an entrepreneur, and disposes of the conception of the entrepreneur as risk bearer". SCHUMPETER, Joseph A. The theory of economic development. New Brunswick, New Jersey: Transaction Publishers, 1983. p. 74-75.

${ }^{50}$ Conforme: "Economic leadership in particular must hence be distinguished from 'invention'. As long as they are not carried into practice, inventions are economically irrelevant. And to carry any improvement into effect is a task entirely different from the inventing of it, and a task, moreover, requiring entirely different kinds of aptitudes. Although entrepreneurs of course may be inventors just as they may be capitalists, they are inventors not by nature of their function but by coincidence and vice versa. Besides, the innovations which it is the function of the entrepreneurs to carry out need not necessarily be any inventions at all. It is, therefore, not advisable, and it may be downright misleading, to stress the element of invention as much as writers do". SCHUMPETER, Joseph A. The theory of economic development. New Brunswick, New Jersey: Transaction Publishers, 1983. p. 88-89.
} 
Schumpeter distingue quatro papéis no processo de inovação: o inventor, quem inventa uma ideia nova; o empreendedor, quem comercializa essa nova ideia; o capitalista, quem fornece os recursos financeiros ao empreendedor (e suporta o risco do projeto de inovação); o gerente, quem cuida da rotina diária da gestão corporativa. ${ }^{51}$

O conceito de implementação de novas combinações de Schumpeter pode ser melhor entendido a partir do seguinte trecho ${ }^{52}$ :

Esse conceito abrange os cinco casos seguintes: (1) A introdução de uma nova mercadoria - com a qual os consumidores ainda não estão familiarizados - ou de uma nova qualidade de uma mercadoria. (2) A introdução de um novo método de produção, ainda não testado pela experiência na área de manufatura considerada, que precisa estar fundamentado em uma descoberta cientificamente nova, e pode também ocorrer por uma nova maneira de manejo comercial de uma mercadoria. (3) A abertura de um novo mercado, um mercado dentro do qual a área particular da produção do país em questão não entrou previamente, tenha o mercado existido ou não anteriormente. (4) A conquista de uma nova fonte de fornecimento de matéria-prima ou mercadorias semi-manufaturadas, novamente independentemente de se essa fonte já existe ou se já foi criada. (5) A implementação de nova organização da indústria, como a criação de uma posição de monopólio (por exemplo através de formação de truste) ou a quebra de uma posição de monopólio. ${ }^{53}$

Vale ressaltar que o conceito de Schumpeter tem grande influência até hoje. Por exemplo, sua influência no conceito da Organização para a Cooperação e Desenvolvimento Econômico é clara:

Empreendedores são aquelas pessoas (donos de negócios) que buscam gerar valor, através da criação ou expansão de atividade econômica, pela identificação e exploração de novos produtos, processos ou mercados. ${ }^{54}$

A quinta corrente intelectual tem o mérito de enfatizar um processo que se serve, em alguma medida, da inovação e da coordenação de mercado, tratadas acima ${ }^{55}$. É a difusão tecnológica. O empreendedor atuaria para difundir na sociedade os benefícios dos avanços tecnológicos produzidos por pesquisa universitária, por exemplo. Ocorreria um processo de

\footnotetext{
51 Tradução livre de: "Schumpeter distinguishes four roles in the process of innovation: the inventor, who invents a new idea; the entrepreneur who commercializes this new idea; the capitalist, who provides the financial resources to the entrepreneur (and bears the risk of the innovation project); the manager, who takes care of the routine day-to-day corporate management". STAM, Erik. Entrepreneurship and Innovation. In: STAM, Erik; NOOTEBOOM, Bart (eds.). Micro-Foundations for Innovation Policy. Amsterdam: Amsterdam University Press, 2008. p. 135.

${ }^{52}$ Para a descrição das características pessoais do indivíduo empreendedor, ver: SCHUMPETER, Joseph A. The theory of economic development. New Brunswick, New Jersey: Transaction Publishers, 1983. p. 85-88.

${ }^{53}$ Tradução livre de: "This concept covers the following five cases: (1) The introduction of a new good - that is one with which consumers are not yet familiar - or of a new quality of a good. (2) The introduction of a new method of production, that is one not yet tested by experience in the branch of manufacture concerned, which need by no means be founded upon a discovery scientifically new, and can also exist in a new way of handling a commodity commercially. (3) The opening of a new market, that is a market into which the particular branch of manufacture of the country in question has not previously entered, whether or not this market has existed before. (4) The conquest of a new source of supply of raw materials or half-manufactured goods, again irrespective of whether this source already exists of whether it has first to be created. (5) The carrying out of the new organization of any industry, like the creation of a monopoly position (for example through trustification) or the breaking up of a monopoly position". SCHUMPETER, Joseph A. The theory of economic development. New Brunswick, New Jersey: Transaction Publishers, 1983. p. 66.

${ }^{54}$ Tradução livre de: "Entrepreneurs are those persons (business owners) who seek to generate value, through the creation or expansion of economic activity, by identifying and exploiting new products, processes or markets". AHMAD, Nadim; SEYMOUR, Richard G. Defining Entrepreneurial Activity: Definitions Supporting Frameworks for Data Collection. OECD Statistics Working Papers, No. 2008/1. Paris: OECD Publishing, 2008. p. 14.

${ }^{55}$ PENEDER, Michael R. The Meaning of Entrepreneurship: Towards a Modular Concept. WIFO Working Papers, No. 335. Viena: WIFO, Março de 2009. p. 10-11. Disponível em: http://www.wifo.ac.at/wwa/servlet/wwa.upload.DownloadServlet/bdoc/WP 2009 335\$.PDF. Acesso em: 26/11/09.
} 
imitação da tecnologia adotada em uma aplicação ou mercado, com sua transferência para outras aplicações ou mercados. Conforme visto acima, a abertura de mercados já foi identificada por Schumpeter como uma das possibilidades da combinação nova dos fatores de produção. Por sua vez, a identificação de demanda por transferência de tecnologia estava contida na abordagem da coordenação de mercado. Ainda, esta corrente afirma que o caráter distintivo dos empreendedores é a habilidade para lidar com a instabilidade. Essa habilidade poderia ser desenvolvida pela educação e experiência ${ }^{56}$, o que chama a atenção para a importância de políticas públicas educacionais específicas ${ }^{57}$.

A penúltima linha teórica se refere ao comportamento de busca e exploração de oportunidades lucrativas, independentemente de serem relacionadas ou não à inovação, ou mesmo se traduzirem em prejuízo à sociedade. William Baumol é representativo da identificação do chamado rent-seeking com o empreendedorismo, e traz uma definição de empreendedorismo que não incorpora o aspecto valorativo positivo geralmente associado ao fenômeno, e incorpora o que chama de empreendedorismo improdutivo. O conceito apresenta resposta frente a um questionamento levantado a partir da concepção de Schumpeter, que abarca como inovação empreendedora a criação de um monopólio, cujo valor para a sociedade é bastante discutível. Admitindo que o empreendedorismo pode gerar ou não benefício social, propõe como problema a alocação dos recursos empreendedores em atividades produtivas, e a formulação de políticas públicas correspondentes:

Mais importante para a discussão aqui, a lista de Schumpeter das atividades
empreendedoras pode ser expandida de maneira útil para incluir tais itens como inovações
em atos de rent-seeking, por exemplo, a descoberta de uma brecha legal anteriormente não
utilizada que é eficaz em desviar verbas para aqueles que forem os primeiros em explorá-
la. Pode parecer estranho à primeira vista propor a inclusão de atividades de valor tão
questionável à sociedade (eu vou chamá-las de atos de "empreendedorismo improdutivo")
na lista das inovações schumpeterianas (ainda que a criação de um monopólio, que
Schumpeter inclui na lista de inovações, seja seguramente questionável), mas, como será
visto em breve, esse é um passo crucial para a análise que segue. Se os empreendedores
forem definidos, simplesmente, por serem pessoas que são engenhosas e criativas em
encontrar formas de acrescentar algo a sua própria riqueza, poder e prestígio, então é
esperado que nem todas elas estarão excessivamente preocupadas com se uma atividade
que atinge esses objetivos acrescenta muito ou pouco para o produto social ou, por essa
razão, mesmo se é na realidade um obstáculo à produção (...). Suponha que ocorra, além
disso, que em qualquer lugar e tempo a magnitude do benefício que a economia retém de
seus talentos empreendedores dependa substancialmente, entre outras variáveis, da
alocação desse recurso entre atividades empreendedoras produtivas e improdutivas dos
tipos acima descritos. Então os motivos para a inclusão de atos do último tipo na lista de

${ }^{56}$ Conforme: "The main purpose of this study is to explore how education and experience influence the efficiency of human beings to perceive, to interpret correctly, and to undertake action that will appropriately reallocate their resources". SCHULTZ, Theodore W. The Value of the Ability to Deal with Disequilibria. Journal of Economic Literature. Vol. 13, No. 3. Pittsburg: American Economic Association, Setembro, 1975. p. 827.

${ }^{57}$ PENEDER, Michael R. The Meaning of Entrepreneurship: Towards a Modular Concept. WIFO Working Papers, No. 335. Viena: WIFO, Março de 2009. p. 10. Disponível em: http://www.wifo.ac.at/wwa/servlet/wwa.upload.DownloadServlet/bdoc/WP 2009 335\$.PDF. Acesso em: 26/11/09. 
atividades empreendedoras ficam claros. ${ }^{58}$

A última linha teórica de nossa exposição é a linha do empreendedorismo corporativo. O foco desta linha é a determinação do locus do empreendedorismo ${ }^{59}$. A primeira questão é saber se o empreendedorismo é uma característica permanente ou temporária. Segundo Peneder, Schumpeter, utilizando a noção de empreendedorismo inovador, argumenta que o sucesso de um empreendedor levará à subsequente expansão da organização, e a tendência é que o empreendedor se torne um gerente nos estágios seguintes do desenvolvimento empresarial. Em outras palavras, o empreendedor assim é caracterizado justamente pela realização da inovação na combinação dos fatores de produção, não como uma classe social ou uma profissão. Por isso, vários estudos empíricos identificam o empreendedorismo com projetos incipientes. Outros modelos consideram todo e qualquer autônomo, ou pessoa que cuida do próprio negócio, como empreendedor ${ }^{60}$.

A segunda questão a respeito do locus do empreendedorismo é sobre sua dinâmica em grandes corporações inovadoras. Os estudos nessa área indicam que a função empreendedora nesses casos emerge da interação entre iniciativas individuais, frequentemente em níveis intermediários da hierarquia empresarial, interessados na ascensão profissional, e o contexto da organização, definido pelo nível mais alto de direção. Paralelamente, o sucesso das empresas na exploração de oportunidades varia de acordo com a definição do contexto estrutural de experimentalismo e seleção de iniciativas da empresa. Consequentemente, o empreendedorismo deixa de ser definido em termos puramente individuais, para ser uma função do contexto da organização em que potencialmente emerge.

Esse é o quadro das linhas teóricas que se pretendia expor, a partir do qual fica clara a variedade de conteúdo imputado ao conceito de empreendedorismo. Frente a esse quadro, pode-se citar uma tentativa de aglutinação dos diversos significados de empreendedorismo em

\footnotetext{
${ }^{58}$ Tradução livre de: "Most important for the discussion here, Schumpeter's list of entrepreneurial activities can usefully be expanded to include such items as innovations in rent-seeking procedures, for example, discovery of a previously unused legal gambit that is effective in diverting rents to those who are first in exploiting it. It may seem strange at first blush to propose inclusion of activities of such questionable value to society (I shall call them acts of 'unproductive entrepreneurship') in the list of Schumpeterian innovations (though the creation of a monopoly, which Schumpeter does include as an innovation, is surely as questionable), but, as will soon be seen, this is a crucial step for the analysis that follows. If entrepreneurs are defined, simply, to be persons who are ingenious and creative in finding ways that add to their own wealth, power, and prestige, then it is to be expected that not all of them will be overly concerned with whether an activity that achieves these goals adds much or little to the social product or, for that matter, even whether it is an actual impediment to production (...). Suppose that it turns out, in addition, that at any time and place the magnitude of the benefit the economy derives from its entrepreneurial talents depends substantially, among other variables, on the allocation of this resource between productive and unproductive entrepreneurial activities of the sorts just described. Then the reasons for including acts of the latter type in the list of entrepreneurial activities become clear". BAUMOL, William J. Entrepreneurship: productive, unproductive, and destructive. In: Journal of Political Economy, Vol. 98 , No. 5. Chicago: The University of Chicago Press, 1990. p. 897-898.

${ }^{59}$ PENEDER, Michael R. The Meaning of Entrepreneurship: Towards a Modular Concept. WIFO Working Papers, No. 335. Viena: WIFO, Março de 2009. p. 12. Disponível em: http://www.wifo.ac.at/wwa/servlet/wwa.upload.DownloadServlet/bdoc/WP_2009_335\$.PDF. Acesso em: 26/11/09.

${ }^{60}$ PENEDER, Michael R. The Meaning of Entrepreneurship: Towards a Modular Concept. WIFO Working Papers, No. 335. Viena: WIFO, Março de 2009. p. 13. Disponível em: http://www.wifo.ac.at/wwa/servlet/wwa.upload.DownloadServlet/bdoc/WP 2009 335\$.PDF. Acesso em: 26/11/09.
} 
um só conceito. Embora seja válido questionar sua capacidade de descrição da complexidade do fenômeno, esta solução tem o mérito de sintetizar em um mesmo contexto grande parte dos temas tratados acima. Abaixo, um exemplo de conceito que faz a referida aglutinação:

Empreendedorismo se refere à habilidade e vontade manifesta de indivíduos, por si próprios, ou em grupos, dentro e fora de organizações preexistentes, de perceber e criar novas oportunidades econômicas (novos produtos, novos métodos de produção, novos modelos organizacionais e novas combinações produto-mercado), e introduzir suas ideias no mercado, enfrentando incerteza e outros obstáculos, e fazendo decisões sobre a alocação, forma e uso de recursos e instituições. ${ }^{61}$

2.2 Empreendedorismo: apoio jurídico e significado institucional da liberdade

De qualquer forma, mesmo temas tão diferentes entre si quanto administração de recursos, propensão ao risco, difusão tecnológica, equacionamento de oferta e demanda do mercado e inovação contém uma linha comum, que lhes dá uniformidade de apoio jurídico: a liberdade. Liberdade entendida como espaço normativo de abertura e proteção à ação do indivíduo em função do risco, da oportunidade, da difusão tecnológica, da inovação, e assim por diante. Este será o eixo condutor da demonstração da relevância jurídica do conceito de empreendedorismo.

Neste ponto, cumpre explicar com mais vagar o significado da tarefa que é posta. Conforme explicado no início do capítulo, o conceito de empreendedorismo é interdisciplinar e, como tal, admite apenas percepções fragmentárias do seu significado, que são ao mesmo tempo independentes e complementares entre si. O conjunto de significados relacionados ao empreendedorismo não se presta a delimitar, enquanto descrição do ser, o que deve ser um suposto direito a empreender, enquanto expressão jurídica do empreendedorismo; nem se presta a oferecer base empírica sobre a qual a análise jurídica incida para detectar um princípio normativo que a sustente, institucionalmente - e nesse sentido a preencha de significado jurídico. Mas, sim, a compor o significado institucional de um princípio jurídico, a liberdade.

Se há relação entre empreendedorismo e liberdade, essa relação, para ser jurídica, tem que partir dos componentes institucionais do princípio jurídico tradicionalmente aceito e,

\footnotetext{
${ }^{61}$ Tradução livre de: "Entrepreneurship is the manifest ability and willingness of individuals, on their own, in teams, within and outside existing organisations to perceive and create new economic opportunities (new products, new production methods, new organisational schemes and new product-market combinations), and to introduce their ideas in the market, in the face of uncertainty and other obstacles, by making decisions on location, form and the use of resources and institutions". WENNEKERS, Sander; THURIK, Roy A. Linking Entrepreneurship and Economic Growth. In: Small Business Economics, Vol. 13. Amsterdam: Kluwer Academix Publishers, 1999. p. 46-47.
} 
ele sim, poderá ser melhor compreendido por um seu componente institucional (um seu instituto jurídico em termos schmittianos), que revele mais uma dimensão obscurecida pela ausência da referência ao conceito de empreendedorismo. Um instituto não é de uma forma por causa de outro; um instituto é um componente cultural que influencia e é influenciado por significados adjacentes. Assim, a liberdade jurídica tem reforço em conceitos ou outras cristalizações culturais institucionais, no caso o empreendedorismo como instituto jurídico aglutinador de enunciados normativos reconhecidos no ordenamento.

O que se procura é a relação principiológica de reforço recíproco entre liberdade jurídica e as dimensões institucionais (manifestações jurídicas) do conceito de empreendedorismo. Dimensões conceituais do empreendedorismo, não o seu significado integral, poderão ser detectadas em dispositivos que servirão, em conjunto com a dimensão maior conceitual de empreendedorismo, como apoio institucional à liberdade jurídica.

O componente principal do empreendedorismo, em sua expressão jurídica, é a livre iniciativa. A livre iniciativa é modalidade da liberdade, esta entendida, segundo Eros Grau, como sensibilidade e acessibilidade a alternativas de conduta e de resultado, em geral. Para o autor, especificamente a liberdade jurídica é que define os limites da manifestação da liberdade em relação a objetos específicos, ou seja, a liberdade artística, religiosa, econômica etc.:

Considerada desde a perspectiva substancial, tanto como resistência ao poder, quanto como reivindicação por melhores condições de vida (liberdade individual e liberdade social e econômica), descrevo a liberdade como sensibilidade e acessibilidade a alternativas de conduta e de resultado. Pois não se pode entender como livre aquele que nem ao menos sabe de sua possibilidade de reivindicar alternativas de conduta e de comportamento - aí a sensibilidade; e não se pode chamar livre, também, aquele ao qual tal acesso é sonegado - aí a acessibilidade.

Examinada, por outro lado, desde a perspectiva institucional, teremos que o traço constitutivo e diferencial da liberdade, modernamente - afirma-o Umberto Cerroni - é o seu caráter jurídico. Existem, como tais, as liberdades, mundanizadas e laicizadas, enquanto objeto de reconhecimento jurídico e sistematização positiva. Vale dizer: o perfil da liberdade - ou os perfis das liberdades, que ela se decompõe em inúmeras espécies: liberdade política, econômica, intelectual, artística, de ensino, de palavra, de ação, etc. - é o definido pela ordem jurídica. ${ }^{62}$

No que diz respeito à livre iniciativa, Eros Grau entende que a liberdade de iniciativa econômica, não necessariamente se reduz à liberdade de empresa, e esta é apenas uma forma de produção entre outras possíveis, como a iniciativa econômica de cooperativas e do Estado, por exemplo ${ }^{63}$. Não obstante ser possível que se manifeste de outras maneiras, entendemos,

\footnotetext{
${ }^{62}$ GRAU, Eros Roberto. A ordem econômica na constituição de 1988 (Interpretação e crítica). 11ª ed. São Paulo: Malheiros, 2006. p. 201202.

${ }^{63}$ GRAU, Eros Roberto. A ordem econômica na constituição de 1988 (Interpretação e crítica). 11ª ed. São Paulo: Malheiros, 2006. p. 202.
} 
com Herren Aguillar, que a livre iniciativa como liberdade de empresa é a regra no Estado brasileiro $^{64}$.

A livre iniciativa é mencionada no texto constitucional como fundamento da República Federativa do Brasil (art. $1^{\circ}$, IV ${ }^{65}$ ) e como fundamento da ordem econômica (art. 170, caput $^{66}$ ). Em relação à livre iniciativa como fundamento da República, Eros Grau ressalta que o valor social a que se refere a Constituição se aplica tanto ao trabalho, em sentido restrito, quanto à livre iniciativa.

Isso significa que a livre iniciativa não é tomada, enquanto fundamento da República Federativa do Brasil, como expressão individualista, mas sim no quanto expressa de socialmente valioso. ${ }^{67}$

Por outro lado, ainda segundo Eros Grau, o artigo 170, caput, expressaria que o trabalho humano é o objeto privilegiado no texto do dispositivo constitucional, prevalecendo sobre os demais elementos da economia de mercado ${ }^{68}$. Entretanto, esta afirmação não relega a livre iniciativa a segundo plano, uma vez que se entende o exercício da livre iniciativa como trabalho em sentido amplo, enquanto atividade que agrega em geral valor e riqueza à sociedade. Nas palavras do autor:

É que a livre iniciativa é um modo de expressão do trabalho e, por isso mesmo, corolária da valorização do trabalho, do trabalho livre - como observa Miguel Reale Júnior - em uma sociedade livre e pluralista. ${ }^{69}$

Vera Helena de Mello Franco corrobora este entendimento ao descrever o empresário como classe especial que produz riqueza através da organização dos fatores de produção:

[O empresário] É quem organiza, exercendo uma função de intermediação e/ou de transformação dentre os fatores da produção, criando riquezas para o mercado (centro de encontro entre a oferta e a demanda dos diversos sujeitos econômicos), e é quem assume o risco econômico e a iniciativa do empreendimento, não se confundindo, nesta qualidade, quer com o capitalista, quer com o titular da força de trabalho [em sentido restrito]. ${ }^{70}$

Ou seja, é reconhecido que a livre iniciativa pode ser entendida como liberdade de exercício profissional, tanto quanto a de qualquer outro trabalhador - visto que se trata, como

\footnotetext{
${ }^{64}$ Conforme o art. 170, p. u., da Constituição Federal de 1988: "É assegurado a todos o livre exercício de qualquer atividade econômica, independentemente de autorização de órgãos públicos, salvo nos casos previstos em lei”. Herren Aguillar corrobora este entendimento: "O Estado somente pode atuar como empresário na medida em que é autorizado pela Constituição ou nos termos de lei que obedeça aos requisitos do art. 173 da Constituição Federal”. HERREN AGUILLAR, Fernando. Controle social de serviços públicos. São Paulo: M. Limonad, 1999. p. 212.

${ }^{65}$ Conforme: "Art. $1^{\circ}$ A República Federativa do Brasil, formada pela união indissolúvel dos Estados e Municípios e do Distrito Federal, constitui-se em Estado Democrático de Direito e tem como fundamentos: (...) IV - os valores sociais do trabalho e da livre iniciativa;".

${ }^{66}$ Conforme: "Art. 170. A ordem econômica, fundada na valorização do trabalho humano e na livre iniciativa, tem por fim assegurar a todos existência digna, conforme os ditames da justiça social, observados os seguintes princípios: (...)”.

${ }^{67}$ GRAU, Eros Roberto. A ordem econômica na constituição de 1988 (Interpretação e crítica). 11 a ed. São Paulo: Malheiros, 2006. p. 200.

${ }^{68}$ GRAU, Eros Roberto. A ordem econômica na constituição de 1988 (Interpretação e crítica). 11 a ed. São Paulo: Malheiros, 2006. p. 200.

${ }^{69}$ GRAU, Eros Roberto. A ordem econômica na constituição de 1988 (Interpretação e crítica). 11 a ed. São Paulo: Malheiros, 2006. p. 206.

${ }^{70}$ FRANCO, Vera Helena de Mello. Manual de Direito Comercial: o empresário e seus auxiliares, o estabelecimento empresarial, as sociedades. Vol. 1. São Paulo: Editora Revista dos Tribunais, 2004. p. 57-58.
} 
dito, de uma atividade de produção de riqueza como qualquer trabalho. Na medida em que produz riqueza, a livre iniciativa tem valor social, e compõe o trabalho humano enquanto fundamento do Estado brasileiro (conforme o art. $1^{\circ}$, IV, da Constituição).

Uma série de significados específicos podem ser agregados à livre iniciativa ${ }^{71}$, classificados como liberdades públicas ou privadas, conforme a natureza da relação, com o Estado ou outros particulares. A primeira categoria é a livre iniciativa como: (i) liberdade de comércio e indústria (não ingerência do Estado no domínio econômico), seja (i.1) faculdade de criar e explorar uma atividade econômica a título privado (liberdade pública), ou (i.2) não sujeição a qualquer restrição estatal senão em virtude de lei (liberdade pública). É a este significado que muitas vezes se referem os autores quando tratam da livre iniciativa, simplesmente. Aqui, o ponto fundamental é a liberdade de iniciativa econômica, em especial a liberdade de empresa. A segunda categoria de significados específicos é a livre iniciativa enquanto livre concorrência, que será analisada separadamente.

Celso Ribeiro Bastos entende que a livre iniciativa deveria ser considerada como direito fundamental ${ }^{72}$, conforme segue:

Na verdade esta liberdade é uma manifestação dos direitos fundamentais e no rol daqueles devia estar incluída. De fato o homem não pode realizar-se plenamente enquanto não lhe for dado o direito de projetar-se através de uma realização transpessoal, vale dizer, por meio da organização de outros homens com vistas à realização de um objetivo. Aqui a liberdade de iniciativa tem conotação econômica. Equivale dizer ao direito que todos têm de lançarem-se ao mercado da produção de bens e serviços por sua conta e risco. Aliás, os autores reconhecem que a liberdade de iniciar a atividade econômica implica a de gestão e a de empresa.

A liberdade de iniciativa e de empresa pressupõe o direito de propriedade da mesma forma que é de certa forma uma decorrência deste. O seu exercício envolve uma liberdade de mercado, o que significa dizer que são proibidos os processos tendentes a tabelar os preços ou mesmo forçar a venda em condições que não sejam as resultantes do mercado. A liberdade de iniciativa exclui a possibilidade de um planejamento vinculante. $O$ empresário deve ser o senhor absoluto na determinação do que deve produzir, como produzir, e por que preço vender. Esta liberdade, como todas as outras de resto, não pode ser exercida de forma absoluta. Há necessidade sim de alguns temperamentos. $\mathrm{O}$ importante, contudo, é notar que a regra é a liberdade. Qualquer restrição a esta há de decorrer da própria Constituição ou de leis editadas com fundamento nela. ${ }^{73}$ (grifos nossos)

Em complemento, Tércio Sampaio Ferraz Júnior, apropriadamente, assim pondera a respeito do valor da livre iniciativa e do trabalho humano, reconhecidos como base da ordem econômica (art. 170 da Constituição):

\footnotetext{
${ }^{71}$ GRAU, Eros Roberto. A ordem econômica na constituição de 1988 (Interpretação e crítica). 11ª ed. São Paulo: Malheiros, 2006. p. 204.

${ }^{72}$ Contra a livre iniciativa como direito fundamental, ver: GRAU, Eros Roberto. A ordem econômica na constituição de 1988 (Interpretação e crítica). $11^{\mathrm{a}}$ ed. São Paulo: Malheiros, 2006. p. 207.

${ }^{73}$ BASTOS, Celso Ribeiro. Comentários à Constituição do Brasil. Vol. 7. São Paulo: Saraiva, 1990. p. 16-17.
} 
Afirmar a livre iniciativa como base é reconhecer na liberdade um dos fatores estruturais da ordem, é afirmar a autonomia empreendedora do homem na conformação da atividade econômica, aceitando a sua intrínseca contingência e fragilidade; é preferir, assim uma ordem aberta ao fracasso a uma 'estabilidade' supostamente certa e eficiente. Afirma-se, pois, que a estrutura da ordem está centrada na atividade das pessoas e dos grupos e não na atividade do Estado. Isto não significa, porém, uma ordem do 'laissez faire', posto que a livre iniciativa se conjuga com a valorização do trabalho humano. mas a liberdade, como fundamento, pertence a ambos. Na iniciativa, em termos de liberdade negativa, da ausência de impedimentos e da expansão da própria criatividade. $\mathrm{Na}$ valorização do trabalho humano, em termos de liberdade positiva, de participação sem alienações na construção da riqueza econômica. Não há, pois, propriamente, um sentido absoluto e ilimitado na livre iniciativa, que por isso não exclui a atividade normativa e reguladora do Estado. Mas há ilimitação no sentido de principiar a atividade econômica, de espontaneidade humana na produção de algo novo, de começar algo que não estava antes. Esta espontaneidade, base da produção da riqueza, é o fator estrutural que não pode ser negado pelo Estado. Se, ao fazê-lo, o Estado a bloqueia e impede, não está intervindo, no sentido de normar e regular, mas está dirigindo e, com isso, substituindo-se a ela na estrutura fundamental do mercado. ${ }^{74}$ (grifo nosso)

O significado de livre iniciativa, no que se refere à prestação de serviços públicos, exige que o Estado não oponha impedimento à liberdade humana no que seja socialmente desejável, conforme se infere da doutrina de Eros Grau:

Neste sentido, social, é que observei, anteriormente - item 39 - que, conotando a expressão atividade econômica, no art. 170, o gênero, e não a espécie (atividade econômica em sentido amplo, pois), toda ela, inclusive a desenvolvida, pelo Estado, no campo dos serviços públicos, deve ser (estar) fundada na valorização do trabalho humano e na livre iniciativa. É ao valor social desta última que me referi então - e ora me refiro. Não quer isso, naturalmente, significar que o serviço público seja de livre iniciativa - ou seja, de iniciativa da empresa privada - mas sim que, na sua prestação deve, aí também, o Estado, não opor empecilho à liberdade humana, no quanto seja socialmente prezável. ${ }^{75}$

Ora, resta claro a partir dos excertos transcritos que a livre iniciativa, enquanto liberdade de produção, se serve de elementos do conceito de empreendedorismo. Especialmente: a capacidade de coordenação de mercado para a satisfação da demanda dos consumidores, a gestão corporativa como organização dos fatores da produção, a assunção do risco, e da responsabilidade correspondente.

Ao conjunto de significados específicos da livre iniciativa, reunidos sob a insígnia da liberdade de comércio e indústria, agrega-se outro conjunto ${ }^{76}$, também dividido em liberdades públicas e privadas, pelo qual a livre iniciativa é vista sob a ótica da: (i) liberdade de concorrência, seja (i.1) faculdade de conquistar a clientela, desde que não através de concorrência desleal (liberdade privada), (i.2) proibição de formas de atuação que deteriam a concorrência (liberdade privada), ou (i.3) neutralidade do Estado diante do fenômeno concorrencial, em igualdade de condições dos concorrentes (liberdade pública). Nela se

\footnotetext{
${ }^{74}$ FERRAZ JÚNIOR, Tércio Sampaio. A economia e o controle do Estado. O Estado de São Paulo. São Paulo, p. 50, 04 jun 1989. apud GRAU, Eros Roberto. A ordem econômica na constituição de 1988 (Interpretação e crítica). 11ª ed. São Paulo: Malheiros, 2006. p. $206-207$.

${ }^{75}$ GRAU, Eros Roberto. A ordem econômica na constituição de 1988 (Interpretação e crítica). 11a ed. São Paulo: Malheiros, 2006. p. 207.

${ }^{76}$ GRAU, Eros Roberto. A ordem econômica na constituição de 1988 (Interpretação e crítica). 11 a ed. São Paulo: Malheiros, 2006. p. 204.
} 
encontra o segundo pilar do empreendedorismo em sua expressão jurídica, que é a valorização da competição, instrumento de realização do bem-estar dos consumidores e da coletividade como um todo - não só pelos preços baixos que provoca como também pelas inovações que impulsiona.

A respeito da livre concorrência, recorremos aos ensinamentos de Tércio Sampaio Ferraz, novamente:

\begin{abstract}
A livre concorrência de que fala a atual Constituição como um dos princípios da ordem econômica (art. 170, IV) não é a do mercado concorrencial oitocentista de estrutura atomística e fluida, isto é, exigência estrita de pluralidade de agentes e influência isolada e dominadora de um ou uns sobre outros. Trata-se, modernamente, de um processo comportamental competitivo que admite gradações tanto de pluralidade quanto de fluidez. É este elemento comportamental - a competitividade - que define a livre concorrência. A competitividade exige, por sua vez, descentralização de coordenação como base da formação dos preços, o que supõe livre iniciativa e apropriação privada dos bens de produção. Neste sentido, a livre concorrência é forma de tutela do consumidor, na medida em que competitividade induz a uma distribuição de recursos a mais baixo preço. De um ponto de vista político, a livre concorrência é garantia de oportunidades iguais a todos os agentes, ou seja, é uma forma de desconcentração de poder. Por fim, de um ângulo social, a competitividade deve gerar extratos intermediários entre grandes e pequenos agentes econômicos, como garantia de uma sociedade mais equilibrada. ${ }^{77}$ (grifo nosso)
\end{abstract}

Vale ressaltar que a livre concorrência resulta em desigualdade de resultados, vencendo o melhor competidor. Entretanto, supõe igualdade de condições no início do jogo, conforme o entendimento de Eros Grau:

A livre concorrência, no sentido que lhe é atribuído - "livre jogo das forças de mercado, na disputa de clientela" -, supõe desigualdade ao final da competição, a partir, porém, de um quadro de igualdade jurídico-formal. Essa igualdade, contudo, é reiteradamente recusada, bastando, para que se o confirme, considerar as disposições contidas no art. 170, IX, no art. 179 e nos $\S \S 1^{\circ}$ e $2^{\circ}$ do art. $171 .^{78}$

Os dispositivos citados pelo autor permitem considerar a proteção à competição como preservação da igualdade de condições, em sentido material, sob dois aspectos. O primeiro deles é a proteção à ordem concorrencial, ou repressão dos abusos do poder econômico. Neste aspecto, o foco é a ação preventiva ou repressiva do Estado no sentido de impedir a formação ou o exercício de poder de mercado, ou abuso de poder econômico ${ }^{79}$. É, portanto, ação direcionada aos blocos econômicos de grande monta, em seu exercício ou formação no mercado. Não basta que os agentes econômicos possam livremente competir no mercado, faz-se necessário regular atividade dos agentes para evitar ações concertadas ou unilaterais que resultem em diminuição da concorrência no mercado.

\footnotetext{
${ }^{77}$ FERRAZ JÚNIOR, Tércio Sampaio. A economia e o controle do Estado. O Estado de São Paulo. São Paulo, p. 50, 04 jun 1989. apud GRAU, Eros Roberto. A ordem econômica na constituição de 1988 (Interpretação e crítica). 11 a ed. São Paulo: Malheiros, 2006. p. 210.

${ }^{78}$ GRAU, Eros Roberto. A ordem econômica na constituição de 1988 (Interpretação e crítica). 11 a ed. São Paulo: Malheiros, 2006. p. 209.

${ }^{79}$ GRAU, Eros Roberto. A ordem econômica na constituição de 1988 (Interpretação e crítica). 11 ${ }^{\mathrm{a}}$ ed. São Paulo: Malheiros, 2006. p. 209212.
} 
Em um segundo aspecto da proteção à competição como preservação de igualdade de condições, em sentido material, a proteção à competição significa proteção à pequena e média empresa, enquanto agente econômico que não concorre em condições de igualdade com os grandes blocos, por razões de cunho político, jurídico e econômico. Ou seja, ao contrário do primeiro aspecto identificado, é uma ação direcionada às pequenas e médias empresas. A manifestação jurídica dessa proteção é identificada como o princípio do tratamento favorecido para as empresas de pequeno porte, ou simplesmente princípio do tratamento favorecido ${ }^{80}$. Conforme segue, a proteção à pequena e média empresa se dá com medidas positivas de incentivo, para criar as condições institucionais para a competição, além de servir de proteção a ente importante no cenário da produção e emprego de uma nação:

Os valores que se pretendem proteger com a política antimonopolista e de protecção à concorrência visam, para além de impedir o domínio político dos grandes grupos industriais, garantir a transparência dos mecanismos de mercado colhendo os benefícios que do ponto de vista do consumidor decorrem de uma certa flutuação dos preços, considerados estes como os veículos mais expeditos e racionais da sua informação econômica, e que do ponto de vista da eficiência da alocação dos recursos destinados ao investimento derivam daquela transparência.

Por sua vez os valores resguardados mediante a política de protecção às P.M.Es [Pequenas e Médias Empresas] são completamente diferentes. A intervenção do Estado pretende criar agora as condições institucionais para que possa exercer-se sem peias o direito de livre empresa do pequeno e médio industrial e comerciante, a favor do qual os Poderes Públicos como que tomam partido.

\section{(...)}

A par dos aludidos valores outros há que justificam também a protecção às P.M.Es

No plano econômico e na medida em que varia de país para país o grau de concentração empresarial, a protecção às P.M.Es é o garante do volume da oferta global, nomeadamente em países como o nosso, em que o peso das P.M.Es no conjunto da economia é determinante. Do mesmo modo e no plano social, é de grande relevo o seu papel na efectivação do pleno emprego e na regionalização do trabalho. ${ }^{81}$

É justamente o comportamento competitivo mencionado por Tércio Sampaio Ferraz a base da procura e exploração de oportunidades característica do empreendedorismo. $\mathrm{Ou}$ seja, a livre concorrência desencadeia o comportamento empreendedor. Nesse sentido, pode ser interpretada como um instrumento do ordenamento que leva em conta o empreendedorismo, como um comportamento socialmente desejável. A competitividade é constituída por esse dinamismo de forças, que lutam para sobrepor-se uma à outra no mercado. Existe o pressuposto, entretanto, de que haja igualdade de condições, dado que

\footnotetext{
${ }^{80}$ KARKACHE, Sergio. Princípio do tratamento favorecido: o direito das empresas de pequeno porte a uma carga tributária menor. Dissertação (Mestrado em Direito) - Programa de pós-graduação em Direito, Universidade Federal do Paraná, Curitiba, PR, 2009. p. 89.

${ }^{81}$ MONCADA, Luis S. Cabral de. Direito económico. 2. ed. Coimbra: Coimbra Ed, 1988. p. 366-367.
} 
apenas concorrem entre si os que se encontram em condições comparáveis. Daí a proteção à concorrência, em sentido material, seja como repressão ao abuso do poder econômico, seja como tratamento diferenciado à pequena e média empresa.

A livre iniciativa e a livre concorrência também se manifestam na prestação do serviço de telecomunicações, objeto específico do presente estudo. São relevantes, para essa análise, sobretudo os dispositivos da Lei 9.472, de 16 de julho de 1997, a Lei Geral de Telecomunicações (“LGT”) ${ }^{82}$. Por exemplo, citamos o art. $2^{\circ}$, incisos III e V, da LGT:

Art. $2^{\circ} \mathrm{O}$ Poder Público tem o dever de:

(...)

III - adotar medidas que promovam a competição e a diversidade dos serviços, incrementem sua oferta e propiciem padrões de qualidade compatíveis com a exigência dos usuários;

(...)

$\mathrm{V}$ - criar oportunidades de investimento e estimular o desenvolvimento tecnológico e industrial, em ambiente competitivo; (grifos nossos)

Aí estão presentes o incentivo à concorrência, diversidade de serviços e desenvolvimento tecnológico, elementos de inovação, e coordenação de mercado, com incremento de oferta e satisfação da demanda por qualidade dos usuários. Como visto anteriormente, estes são elementos do empreendedorismo.

Outros dispositivos seguem na mesma linha, todos da LGT:

Art. $6^{\circ}$ Os serviços de telecomunicações serão organizados com base no princípio da livre, ampla e justa competição entre todas as prestadoras, devendo o Poder Público atuar para propiciá-la, bem como para corrigir os efeitos da competição imperfeita e reprimir as infrações da ordem econômica.

(...)

Art. 71. Visando a propiciar competição efetiva e a impedir a concentração econômica no mercado, a Agência poderá estabelecer restrições, limites ou condições a empresas ou grupos empresariais quanto à obtenção e transferência de concessões, permissões e autorizações.

\section{(...)}

Art. 127. A disciplina da exploração dos serviços no regime privado terá por objetivo viabilizar o cumprimento das leis, em especial das relativas às telecomunicações, à ordem econômica e aos direitos dos consumidores, destinando-se a garantir:

I - a diversidade de serviços, o incremento de sua oferta e sua qualidade;

II - a competição livre, ampla e justa;

(...)

\footnotetext{
${ }^{82}$ Os dispositivos são indicados por Carlos Ari Sundfeld: SUNDFELD, Carlos Ari. Meu depoimento e avaliação sobre a Lei Geral de Telecomunicações. Revista de Direito de Informática e Telecomunicações, v. 02, 2007. p. 70.
} 
IX - o desenvolvimento tecnológico e industrial do setor;

\section{(...)}

Art. 129. O preço dos serviços será livre, ressalvado o disposto no $\S 2^{\circ}$ do art. 136 desta Lei, reprimindo-se toda prática prejudicial à competição, bem como o abuso do poder econômico, nos termos da legislação própria.

(...)

Art. 136. Não haverá limite ao número de autorizações de serviço, salvo em caso de impossibilidade técnica ou, excepcionalmente, quando o excesso de competidores puder comprometer a prestação de uma modalidade de serviço de interesse coletivo. (grifos nossos)

Merece menção à parte a regulamentação do direito de acesso às redes de concorrentes. Considerando a natureza do serviço de telecomunicações, tão mais valioso quanto maior o número de pontos que ligue, isto é, quanto maior a rede, esta regulamentação é fundamental para permitir a entrada de empresas potencialmente competitivas. Vejamos os seguintes dispositivos da LGT:

Art. 110. Poderá ser decretada intervenção na concessionária, por ato da Agência, em caso de:

(...)

VI - recusa injustificada de interconexão;

(...)

Art. 146. As redes serão organizadas como vias integradas de livre circulação, nos termos seguintes:

I - é obrigatória a interconexão entre as redes, na forma da regulamentação;

$(\ldots)$

Art. 150. A implantação, o funcionamento e a interconexão das redes obedecerão à regulamentação editada pela Agência, assegurando a compatibilidade das redes das diferentes prestadoras, visando à sua harmonização em âmbito nacional e internacional.

(..)

Art. 155. Para desenvolver a competição, as empresas prestadoras de serviços de telecomunicações de interesse coletivo deverão, nos casos e condições fixados pela Agência, disponibilizar suas redes a outras prestadoras de serviços de telecomunicações de interesse coletivo.

Diante do exposto, pode-se concluir que há largo apoio jurídico a elementos próprios ao empreendedorismo, inclusive na legislação específica do setor de telecomunicações. Neste caso, têm destaque os elementos de incentivo à competição, livre, justa e ampla, o desenvolvimento tecnológico e industrial do setor, ampliação da oferta, diversificação dos serviços e satisfação da demanda por qualidade do usuário. Além disso, é obrigatório o acesso às redes, por meio da chamada interconexão. Todas essas pretensões jurídicas passam por ao 
menos um sentido de iniciativa empreendedora, ou sustentam um comportamento empreendedor - seja ele relativo à inovação, coordenação de mercado, administração de recursos, difusão de tecnologias, propensão ao risco, ou simplesmente a propriedade de uma pequena empresa. Em todos os casos, o empreendedorismo é reforçado como expressão da livre iniciativa, e reforça essa liberdade jurídica, revelando uma dimensão do seu significado.

Definidos os elementos do empreendedorismo, e sua relevância jurídica, está confirmada a hipótese de que o conceito de empreendedorismo serve como critério normativo para a determinação do grau de concentração regulatória normativa. O empreendedorismo requer a livre iniciativa e a livre concorrência, e realiza o valor social destes institutos, de produção de riqueza e bem-estar, inclusive na prestação de serviços públicos. Isto lhe dá o caráter de interesse público, enquanto realização dos princípios estruturantes da ordem econômica constitucional ${ }^{83}$. Na classificação de Floriano Peixoto de Azevedo Marques $\mathrm{Neto}^{84}$, seu caráter de interesse público pode ser tanto especial quanto difuso, a depender da presença ou não de grupos de pressão definidos, e da ênfase dada a cada aspecto do fenômeno, enquanto inovação, de interesse manifestamente difuso, ou criação e manutenção de pequenas e médias empresas, um interesse manifestamente especial, por exemplo.

De qualquer maneira, o resultado é a legitimidade do uso do conceito de empreendedorismo para dimensionar a gradação da concentração regulatória normativa: por este critério, via de regra, esta será tão desconcentrada quanto possível, para criar o espaço de liberdade normativa, de ausência regulamentar que possibilita o comportamento empreendedor. Esta consequiência da aplicação do conceito de empreendedorismo é cotejada no caso concreto com as conseqüências de outros interesses públicos, sendo o papel da Administração justamente o de mediar esses interesses ${ }^{85}$. Pode ocorrer, no entanto, que a conseqüência da aplicação do conceito seja distinta, e não resulte em abertura de espaço normativo: como visto, a preservação da concorrência, em sentido material, possibilita o comportamento empreendedor, e demanda concentração regulatória normativa do Estado. Nesse microcosmo, portanto, a conseqüência é oposta ao apontado acima e, ainda assim, compatível com preservação das condições institucionais que abrem espaço ao comportamento empreendedor e compõem o significado institucional da liberdade do indivíduo.

\footnotetext{
${ }^{83}$ MARQUES NETO, Floriano Peixoto de Azevedo. Regulação estatal e interesses públicos. São Paulo: Malheiros, 2002. p. 161.

${ }^{84}$ MARQUES NETO, Floriano Peixoto de Azevedo. Regulação estatal e interesses públicos. São Paulo: Malheiros, 2002. p. $161-162$.

${ }^{85}$ MARQUES NETO, Floriano Peixoto de Azevedo. Regulação estatal e interesses públicos. São Paulo: Malheiros, 2002. p. 158.
} 
Esse significado é construído não só a partir das relações entre o ordenamento e cristalizações culturais, mas também a partir das práticas institucionais que se apóiam e são criticadas por meio de tais relações. Assim, resta-nos analisar base empírica representativa da prática institucional no setor de telecomunicações, e verificar eventuais conseqüências do quanto foi dito na interpretação da regulamentação em vigor - o que será feito no capítulo seguinte. 


\section{Possibilidade de aplicação do conceito de empreendedorismo: o caso "Actium"}

Este capítulo pretende demonstrar uma possibilidade de aplicação relevante do conceito de empreendedorismo na interpretação da regulamentação que incide sobre determinado serviço de telecomunicação. A descrição dos fatos relevantes do caso concreto será seguida de análise jurídica da fundamentação da decisão, aproveitando-se os esforços empreendidos nos capítulos anteriores.

\subsection{Descrição do caso "Actium"}

O caso diz respeito a pedido de outorga de autorização para prestação do Serviço Móvel Especializado (“SME”) utilizando radiofrequência com destinação em caráter primário ao Serviço Móvel Pessoal (“SMP”). Embora tenha havido sucessivas aprovações dos órgãos envolvidos no processo de autorização, a matéria não foi analisada de pronto pelo Conselho Diretor da Anatel, que a devolveu ao órgão de origem para mais estudos. Este, por sua vez, não encaminhou as informações solicitadas pelo Conselho Diretor, e indeferiu o pedido da empresa solicitante, arquivando o processo. Ao final, o Conselho Diretor analisou a matéria, reforçando o despacho de arquivamento. Na ocasião, foi sinalizado que a Anatel estudaria a possibilidade de editar regulamentação explícita para a hipótese objeto de análise. Este é o argumento principal da decisão: a ausência de regulamentação explícita da hipótese. Admitindo a necessidade de regulamentação explícita da matéria, a decisão nega legitimidade a interpretação possível da regulamentação vigente e não leva em conta as consequências competitivas benéficas do pedido da empresa, ambas reconhecidas pelas áreas técnicas da Anatel. Segue, passo a passo, o desenrolar dos fatos relevantes para o presente estudo.

Em 19 de abril de 2001, a empresa Actium Telecomunicações Ltda. ("Requerente”) solicitou autorização para prestação de SME, mediante uso industrial da integralidade da rede de acesso rádio, prescindindo da outorga de autorização de uso de radiofrequência ${ }^{86}$. O pedido de autorização foi protocolado sob o n ${ }^{\circ} 53500.002099 / 2002$.

\footnotetext{
${ }^{86}$ De acordo com o Informe $\mathrm{n}^{\circ} 11$ PVCPR/PVCP/SPV, de 19 de fevereiro de 2002, às fls. 190 dos autos do Processo Anatel $\mathrm{n}^{\circ}$ 53500.002099/2002: “4.27 Na exploração industrial, a prestadora interessada contrata serviços (conforme Decreto 2.197/97) de outra prestadora para prestar o seu próprio serviço. No caso da Actium Telecomunicações, há pretensão de fazer uso da radiofreqüência de uma outra prestadora de outro serviço (SMP) [Serviço Móvel Pessoal]".
} 
A Gerência Geral de Comunicações Pessoais Terrestres ("PVCP”) da Superintendência de Serviços Privados ("SPV"), por meio do Informe $\mathrm{n}^{\mathrm{o}} 11$ PVCPR/PVCP/SPV, de 19 de fevereiro de 2002, manifestou-se favoravelmente ao pedido da empresa, afirmando que a autorização para prestação do serviço traria "alternativa de competição em um segmento que hoje está, praticamente, monopolizado pela NEXTEL, onde não há alternativa tecnológica nem radiofreqüência em condições estruturadas, especialmente nas grandes metrópoles". A agência ainda manifestou intenção de acompanhar as consequências da introdução do modelo no mercado, nos termos seguintes:

4.35 Vale ressaltar que, do ponto de vista da Anatel, promover a competição no mercado corporativo, que resulta no aumento da competitividade do setor produtivo do país é de suma importância, onde o serviço de despacho, seja na área de segurança, seja no de transporte de cargas ou de infra-estrutura, desempenha papel fundamental.

4.26 Com isso, constata-se que os pequenos e médios prestadores de SME e aqueles que possuem o SLMP [Serviço Limitado Móvel Privado] estão a enfrentar dificuldades, causado pelo mercado restrito, pela tecnologia analógica, assim como pela concorrência dos grandes prestadores de SME. Estes, por outro lado, estão a sofrer pela concorrência dos Planos Alternativos de Serviço das prestadoras de SMC [Serviço Móvel Celular], pela dificuldade de negociação de interconexão e pela escassez de faixa disponível para crescimento.

4.27 Acrescenta-se, ainda, que, com a saída da Ericsson, a faixa de $800 \mathrm{MHz}$, na tecnologia digital ficou exclusiva do produto iDen da Motorola que tem na Nextel a sua compradora, praticamente em regime de monopólio.

4.38 Por fim, tem-se que a Actium Telecomunicações, que pretende competir com a Nextel nas grandes metrópoles, necessita de alternativa tecnológica e, assim, diante da escassez de espectro, propõe a utilização das radiofreqüências licenciadas a outras operadoras (SMP) [Serviço Móvel Pessoal], para a prestação de SME, o que promoveria o aumento da eficiência do uso do espectro, bem como ampliaria o atendimento para um número cada vez maior de usuários.

$(\ldots)$

5.1.1 A Actium solicita autorização para exploração do SME, trazendo alternativa de competição em um segmento que hoje está, praticamente, monopolizado pela NEXTEL, onde não há alternativa tecnológica nem radiofreqüência em condições estruturadas, especialmente nas grandes metrópoles.

5.3 Cabe destacar que no mercado mundial já ocorre a introdução de prestadoras que recebem a autorização de serviço independente de radiofreqüência (MVNO - Mobile Virtual Network Operator). Tal inovação encontra-se ainda em debate em vários países, em que os principais pontos são os impactos relativos aos aspectos concorrenciais, econômicos e regulatórios.

5.4 Em função disso, apresentamos as seguintes alternativas para apreciação por parte da Procuradoria:

5.4.1 Autorizar a Actium a explorar o SME, mediante a renúncia expressa e antecipada desta às radiofreqüências associadas.

5.4.2 Limitar o número máximo de usuários da Actium a 600.000 (seiscentos mil) a nível nacional e a 250.000 (duzentos e cinqüenta mil) por Área de Registro, devendo eventual 
acréscimo ser expressamente aprovado pela ANATEL e após o prazo de 3 (três) anos da expedição do Termo de Autorização.

5.4.3 Eventuais alterações na regulamentação podem ser adotadas após verificação das alterações introduzidas no mercado por este tipo de procedimento. ${ }^{87}$ (grifo nosso)

O processo foi então encaminhado à Procuradoria da Anatel, que emitiu em 8 de março de 2002 o Parecer no 080/2002-PRC. O parecer esclarece o caráter inovador da solicitação da Requerente, admitindo que, até então, não se havia conferido interpretação à legislação que permitisse a implementação de um serviço móvel mediante uso industrial da integralidade da rede de acesso rádio. De qualquer maneira, o parecer entende pela legalidade da nova interpretação, como deixa claro o seu trecho final:

Nesse caso [uso industrial de meios], de fato, a empresa ficaria dispensada da outorga relativa ao uso da radiofreqüência; permaneceria comprometida, contudo, perante a Agência e os usuários, na exploração e execução do SME, utilizando-se do fornecimento dos serviços de outra outorgada de telecomunicações, no tocante à transmissão. Juridicamente, a hipótese é amparada pelos dispositivos acima mencionados [art. $6^{\mathrm{O}}$ do Decreto $n^{\circ}$ 2.197, de 1997, e art. 60 da Resolução nº 73, de 1998].

No que tange o aspecto do uso compartilhado de radiofreqüência, contudo, tem-se a ressaltar que, apesar de previsto na legislação pertinente, o compartilhamento pressupõe o uso conjunto de um mesmo meio por mais de um outorgado. Por conseguinte, o interessado não poderia fazer uso desta facilidade se não possuísse a autorização para o uso da radiofreqüência correspondente.

$(\ldots)$

Não obstante, como foi dito anteriormente, isso não impede que haja uma nova leitura na legislação, e que o entendimento até então vigente seja revisto. Todavia, deve-se ter em mente que a nova leitura aproveitará todas as situações futuras e não um caso específico. ${ }^{88}$

Estas conclusões foram corroboradas pelo Parecer $\mathrm{n}^{\mathrm{o}}$ 394/2002-PGF/PFADTB/Anatel, emitido em 30 de setembro de 2002, em que "propõe-se o acolhimento da pretensão da entidade requerente" ${ }^{, 89}$.

A viabilidade jurídica do pleito da Reclamante foi ainda atestada na Matéria para Apreciação do Conselho Diretor n ${ }^{\circ}$ 98, de 8 de maio de 2002, que no item 3.11 diz "entendese que a Actium possa compartilhar radiofreqüências com qualquer prestadora de serviço de telecomunicações de interesse coletivo quando permitido pela regulamentação específica do referido serviço" $" 90$. Esse documento ainda houve por ratificar os benefícios tecnológicos e concorrenciais advindos na entrada da Reclamante no mercado de SME, findando por propor ao Conselho Diretor o "atendimento da solicitação da Actium de expedição de Autorização de

\footnotetext{
${ }^{87}$ Fls. 191-193 dos autos do Processo Anatel n ${ }^{\text {o }} 53500.002099 / 2002$.

${ }^{88}$ Fls. 197-198 dos autos do Processo Anatel no 53500.002099/2002.

${ }^{89}$ Fls. 277 dos autos do Processo Anatel no 53500.002099/2002.

${ }^{90}$ Fls. 234 dos autos do Processo Anatel no 53500.002099/2002.
} 
SME, para todo o território nacional, mediante a desistência expressa e antecipada desta às radiofrequiências associadas" $" 1$, o que já havia sido sugerido pela própria empresa. A matéria sugere um acompanhamento dos efeitos da prestação do serviço sob essa modalidade, como seria natural, enfatizando que o incremento à competição é o fator relevante para a autorização do serviço:

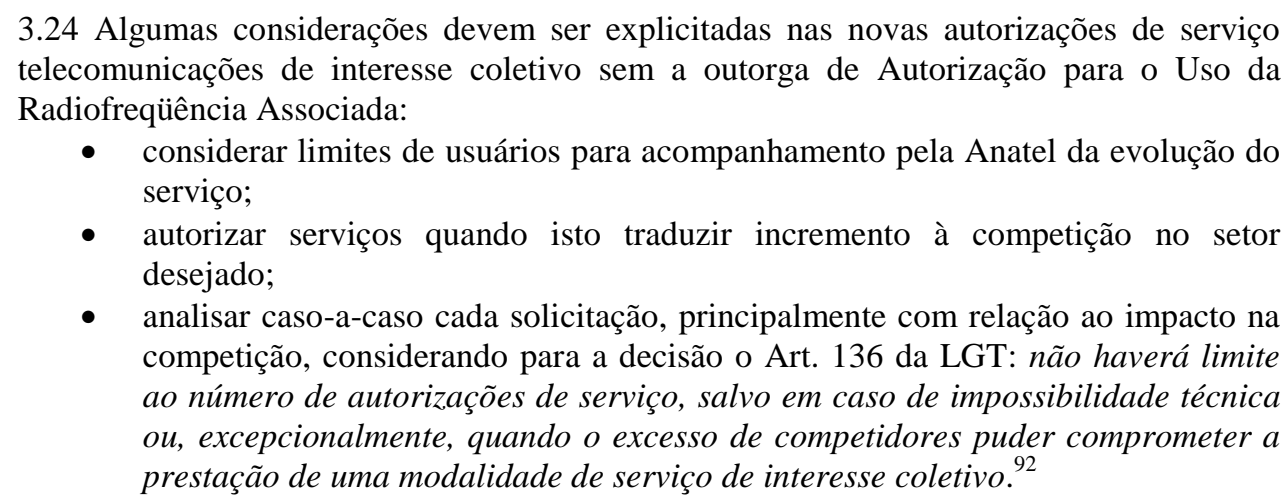

Entretanto, mesmo estando devidamente instruído para análise final pelo órgão responsável, o Conselho Diretor da ANATEL, este não se pronunciou formalmente - embora conste nos autos correspondência eletrônica em que se registra a posição preliminar do Conselheiro-Relator pela possibilidade do deferimento da autorização ${ }^{93}$. Então, foi juntada aos autos nova manifestação da PVCP (Informe $\mathrm{n}^{\circ}$ 58, de 18 de setembro de $2002^{94}$ ), na qual novamente se decide pelo deferimento do pedido da Requerente. Entretanto, desta vez são oferecidas duas alternativas para escolha pelo Conselho Diretor ${ }^{95}$ : a primeira, a aprovação imediata do pleito da Requerente, outorgando-lhe autorização com eficácia condicionada à apresentação de contrato particular de uso industrial de meios (item 4.5.1); a segunda, submeter norma específica à consulta pública para regular a matéria (item 4.5.2).

Em seguida, a matéria foi encaminhada para apreciação do Conselho Diretor. Contudo, em 13 de abril de 2003, o Conselheiro-Relator devolveu o processo à SPV para a realização de estudos adicionais com vistas a um melhor enquadramento da solicitação da Reclamante dentro da regulamentação existente.

Ao invés de serem providas informações ao Conselheiro-Relator, houve o arquivamento do processo pela Gerência de Regulamentação (“PVCPR”), órgão vinculado à PVCP e à SPV. Tal decisão foi comunicada por meio do ofício n ${ }^{\circ}$ 57/2003/PVCPR-ANATEL,

\footnotetext{
${ }^{91}$ Fls. 237 dos autos do Processo Anatel no 53500.002099/2002.

${ }_{92}$ Fls. 237 dos autos do Processo Anatel no $53500.002099 / 2002$.

${ }^{93}$ Fls. 259 dos autos do Processo Anatel no 53500.002099/2002.

${ }^{94}$ Fls. 239 a 244 dos autos do Processo Anatel no 53500.002099/2002.

${ }^{95}$ Fls. 240 dos autos do Processo Anatel no 53500.002099/2002.
} 
datado de 7 de julho de $2003^{96}$. Em resumo, o documento constrói uma argumentação essencialmente jurídica, para concluir pela impossibilidade de enquadrar o pedido da Actium na regulamentação vigente, e indefere o pedido da Requerente. Em seguida, relata-se que novos estudos serão feitos para verificar a possibilidade de autorização de prestação do serviço da forma solicitada pela Requerente:

2.28 Salientamos que, com a apresentação da supracitada petição, de 13 de junho de 2003, que consiste em retorno à proposta original feita pela Requerente, no Processo Administrativo ${ }^{\circ}$ 53500.002099/2002, estudos e análises foram feitos por esta Gerência que, tendo em vista a impossibilidade de enquadrar o pedido da Actium na regulamentação atual, decide pelo indeferimento do pedido e conseqüente encerramento do presente Processo Administrativo.

2.29 Entretanto, estudos acerca do tema (possibilidade de autorização para exploração do Serviço Móvel Especializado sem a outorga da radiofreqüência que lhe é afeta) continuam sendo realizados e serão submetidos à apreciação do Conselho Diretor, em atendimento ao MM. 130/2003 - GCJL, de 13 de abril de 2003.

Inconformada, a Requerente optou pela interposição de recurso, dirigido ao Conselho Diretor. O recurso não foi conhecido por intempestividade e o processo, arquivado, conforme

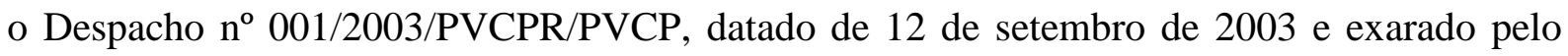
Gerente-Geral de Comunicações Pessoais Terrestres. Não obstante, após aviamento de reclamação administrativa, a matéria foi encaminhada ao Conselho Diretor, que, no mérito, se limitou a reforçar os argumentos do ofício no 57/2003/PVCPR-ANATEL. Merece destaque o seguinte trecho da análise do Conselheiro-Relator:

Assim, a solicitação da Actium é para um serviço que não existe, pois um SME sem radiofreqüências é uma contradição dos próprios termos.

Cabe sempre lembrar que a Administração Pública só pode fazer o que a lei e a regulamentação permitem e é uma obrigação da Anatel o respeito às normas administrativas, especialmente àquelas por ela mesma editadas, cujos preceitos não podem ser descumpridos nem mesmo por acordo ou vontade conjunta de seus aplicadores e destinatários, uma vez que contém verdadeiros poderes-deveres, irrelegáveis pelos agentes públicos.

Ademais, a interpretação das normas relativas a telecomunicações é de competência da Anatel que, exercendo este poder-dever visando o interesse público, impede que o sentido da regulamentação dos serviços que fiscaliza seja distorcido, pelas empresas interessadas, de forma a adequá-lo melhor a seus anseios particulares.

\section{$(\ldots)$}

Por último, gostaria de comentar sobre o possível interesse em modificar a regulamentação para permitir a prestação de serviço móvel sem a outorga direta de radiofreqüências. A introdução do operador móvel virtual (MVNO - Mobile Virtual Network Operator) parece ser uma boa solução para aumentar a eficiência no uso do espectro e a penetração, principalmente do Serviço Móvel Pessoal - SMP, em cidades de

\footnotetext{
${ }^{96}$ Fls. 305 dos autos do Processo Anatel n ${ }^{\circ} 53500.002099 / 2002$.
} 
pequeno porte. Tendo em vista o sucesso do MVNO, principalmente nos países escandinavos, a Anatel deverá estudar as vantagens e desvantagens de tal inovação e, se for o caso, introduzir tal tipo de autorização no arcabouço regulatório brasileiro. ${ }^{97}$

Assim, o Conselho Diretor decidiu indeferir o pedido de outorga de autorização para prestação do serviço e encerrar definitivamente o processo, por meio do Despacho $\mathrm{n}^{\circ}$ 063/2006-CD, de 6 de fevereiro de $2006^{98}$. A decisão foi devidamente encaminhada ao representante legal da Requerente, e os autos foram arquivados definitivamente em 21 de março de $2006^{99}$.

\subsection{Análise jurídica do caso selecionado}

O objetivo desta seção é a análise jurídica do caso Actium, acima descrito. Como dito explicitamente no Despacho n ${ }^{\circ}$ 063/2006-CD, de 6 de fevereiro de 2006, do Conselho Diretor da Anatel, o fundamento para o indeferimento da outorga de autorização para a prestação do SME é a "impossibilidade do pedido ser enquadrado na regulamentação atual" ${ }^{\prime 00}$. Não se pretende discutir o mérito desta afirmação, ou seja, se a Anatel acertou ou não ao entender que o pedido não se enquadrava na regulamentação, visto que o assunto já foi exaustivamente debatido nos autos. Está demonstrada a incongruência entre diversas manifestações dos órgãos da Anatel e a decisão do Conselho Diretor, em relação à possibilidade de interpretação da regulamentação vigente em favor da Requerente. Neste ponto, não teríamos inovação a fazer, e os autos estão disponíveis para análise de qualquer interessado. $\mathrm{O}$ que se pretende é discutir a própria validade do indeferimento do pedido fundamentado pelo não enquadramento da hipótese na regulamentação vigente.

Em primeiro lugar, e em conformidade com o exposto acima, a livre iniciativa, como expressão do empreendedorismo, impõe que, mesmo na prestação de serviços públicos, a liberdade do indivíduo não seja limitada no que seu exercício seja socialmente desejável ${ }^{101}$. Ou seja, a simples falta de regulamentação explícita não é suficiente para a recusa da outorga da autorização, que precisa ser motivada em prejuízos à concorrência, à segurança na prestação do serviço ou outros fundamentos, visto que a regra é a liberdade de iniciativa, que faz parte do comportamento empreendedor.

No caso, a análise dos órgãos competentes deixa claro nos autos que a

\footnotetext{
${ }^{97}$ Fls. 460 dos autos do Processo Anatel no 53500.002099/2002.

${ }_{98}^{9}$ Fls. 463 dos autos do Processo Anatel n ${ }^{\circ} 53500.002099 / 2002$.

${ }^{99}$ Fls. 467 dos autos do Processo Anatel no 53500.002099/2002.

${ }^{100}$ Fls. 463 dos autos do Processo Anatel $\mathrm{n}^{\mathrm{o}} 53500.002099 / 2002$.

${ }^{101}$ GRAU, Eros Roberto. A ordem econômica na constituição de 1988 (Interpretação e crítica). 11 ${ }^{\text {a }}$ ed. São Paulo: Malheiros, 2006. p. 207.
} 
implementação da modalidade da prestação do serviço solicitada pela Requerente é benéfica do ponto de vista competitivo, com possibilidade de contestação da posição de quase monopólio da Nextel (85\% do mercado à época), uso eficiente do espectro e ampliação da base de usuários ${ }^{102}$. Como o SME se destina ao mercado corporativo, essa medida tem impactos econômicos significativos, advindos dos ganhos de produtividade gerados pelo uso intensivo de tecnologias da informação e comunicação ("TICs") ${ }^{103}$. Além disso, a utilização do modelo proposto pela Actium, de operadora móvel virtual (Mobile Virtual Network Operator - $M V N O$ ), foi considerada nos autos como potencialmente eficaz na expansão do serviço para cidades de pequeno porte ${ }^{104}$, argumento que confirma a importância do compartilhamento de radiofrequência. Além disso, o modelo de compartilhamento de radiofrequência não é totalmente estranho à prática institucional da Anatel. No passado, a Telemar pôde implementá-lo, por meio do uso industrial da rede de acesso rádio da Oi, para prestar Serviço Telefônico Fixo Comutado (Resolução Anatel n 278, de 15 de outubro de $2001)^{105}$.

Tampouco há preocupações legítimas que recomendem observação da agência em relação à segurança na prestação do serviço ao usuário, simplesmente porque não se faria uso inédito da radiofrequência, e sim da integralidade da rede de acesso rádio da empresa prestadora de SMP que, presumivelmente, já trabalhava em total acordo com a regulamentação vigente. A única preocupação regulatória que se justificaria seria com o comportamento do mercado, entretanto, a própria Anatel sugere impor limite de usuários ao serviço como maneira de acompanhar a atividade do modelo ${ }^{106}$. Sem discutir o mérito dessa forma de acompanhamento, o fato é que uma solução para a necessidade de acompanhamento do mercado foi proposta pelos órgãos instrutores da Anatel em antecipação a eventual preocupação do Conselho Diretor. Essa questão sequer foi levantada em sua decisão.

Pode-se inferir também que, a partir do Informe no 58 PVCPR/PVCP/SPV, de 18 de setembro de $2002^{107}$, a preocupação com a isonomia levou ao questionamento da alternativa que melhor atenderia o interesse público: autorização da prestação do serviço nos termos em que solicitou a Actium ou realização de estudos para avaliar a proposta de norma que regulamente a matéria explicitamente, a ser submetida a consulta pública. O referido informe argumenta que a consulta pública "assegura a participação de toda a sociedade e oferece a

\footnotetext{
${ }^{102}$ Fls. 191-192 dos autos do Processo Anatel no $53500.002099 / 2002$.

${ }^{103}$ Fls. 191-192 dos autos do Processo Anatel no $53500.002099 / 2002$.

${ }^{104}$ Fls. 460 dos autos do Processo Anatel no 53500.002099/2002.

${ }^{105}$ A informação foi citada em parecer juntado aos autos do Processo Anatel no 53500.002099/2002, às fls. 358.

${ }^{106}$ Limite sujeito a revisão mediante aprovação pela agência. Fls. 193 e 237 dos autos do Processo Anatel no $53500.002099 / 2002$.

${ }^{107}$ Fls. 239 a 244 dos autos do Processo Anatel no $53500.002099 / 2002$.
} 
oportunidade a outros interessados no mesmo tipo de solicitação, o que reflete a aplicação do Princípio da Isonomia, bem como da Impessoalidade, uma vez que, a Norma, aplicar-se-á a todos e não se prestará para atender a uma situação específica"108.

No entanto, viu-se que o interesse público, em sua complexidade, é potencialmente definido apenas no caso concreto, fruto da mediação entre interesses públicos identificados à primeira vista pela Administração. Isto elimina suposta falta necessária ao princípio da isonomia no deferimento de pedido inédito de outorga de autorização para a prestação de serviço de telecomunicações, em hipótese ainda não discutida em consulta pública. $\mathrm{O}$ significado da isonomia deve ser considerado no contexto de outros significados em jogo, entre eles o conceito de empreendedorismo, no que este se relaciona a princípios do ordenamento jurídico.

Já foi dito que a percepção pioneira das oportunidades disponíveis é um elemento constitutivo do empreendedorismo. No caso em análise, a oportunidade percebida pela Actium já estava presente como possibilidade no ordenamento, presumivelmente acessível a todos, uma vez que, conforme nosso entendimento, o princípio da livre iniciativa prescreve a não limitação, de antemão, da iniciativa privada, inclusive na prestação de serviços públicos. Adicionalmente, foi reconhecida no âmbito Anatel a legitimidade da interpretação da Actium da possibilidade da prestação do serviço a partir dos elementos existentes na regulamentação vigente (também presumivelmente acessível a todos). Assim, no contexto do caso, o significado da isonomia é a igualdade de condições de acesso à informação necessária para a percepção da oportunidade empreendedora.

Ademais, a própria Anatel sugere que se faça uma análise caso a caso desse tipo de pedido $^{109}$, e indica que o benefício à competição é um fator a ser levado em consideração para a outorga da autorização em casos semelhantes. Ou seja, a agência reconhece que é possível se fazer a análise caso a caso, e antecipa um elemento importante como argumento nesses casos: o benefício à competição - ainda que em eventual contraposição a um significado possível de igualdade. Por outro lado, a prática institucional da agência mostra que situação semelhante havia sido permitida no passado ${ }^{110}$, presumivelmente em atendimento a interesses legítimos do ponto de vista regulatório. O mesmo poderia ter ocorrido no caso analisado. Deste modo, a observância da isonomia não é um impedimento à outorga da autorização à Actium, seja porque o significado de isonomia no contexto do caso é de igualdade de acesso

\footnotetext{
${ }^{108}$ Fls. 243 dos autos do Processo Anatel no 53500.002099/2002.

${ }^{109}$ Fls. 237 dos autos do Processo Anatel no 53500.002099/2002.

${ }^{110}$ Ver a Resolução Anatel n 278, de 15 de outubro de 2001, citada acima.
} 
às informações relevantes para a percepção da oportunidade, seja porque a própria isonomia pode ser preterida, caso se entenda que outros princípios melhor realizem o interesse público.

A percepção aguçada de oportunidades, como elemento central do empreendedorismo, em seus vários significados, deve ser incentivada. Não só pelos benefícios sociais que traz. É que este elemento pode ser identificado como dimensão do significado dos princípios estruturantes de nossa ordem econômica, especialmente a liberdade de iniciativa e de concorrência. $\mathrm{O}$ conceito de empreendedorismo, nesse contexto, serve de unificador de significados - na medida em que compatibiliza as consequências aparentemente opostas dos princípios da livre iniciativa e livre concorrência, em sentido material, de abertura de espaços normativos e intervenção na liberdade do particular, proibindo à atividade estatal que diminua a competitividade, ou incentivando aqueles que não têm condições de concorrer em pé de igualdade. O conceito tem o mérito de ressaltar o resultado a que os princípios da livre iniciativa e livre concorrência se vinculam, enquanto faces de um mesmo propósito institucional. Isto certamente auxilia a determinar seus significados para a ordem jurídica em geral e para os casos concretos com que se depara a Administração. Esse é o diferencial de sua aplicação.

Como se vê, a aplicação do conceito de empreendedorismo ao caso em tela produz uma alteração radical na interpretação da regulamentação em vigor, dado que não basta que a Anatel identifique a ausência de regulamentação explícita a respeito de um determinado serviço para que deixe de emitir a correspondente autorização. A regra é a livre iniciativa, expressão do empreendedorismo. É necessário que sejam demonstrados especificamente outros interesses públicos prejudicados pela autorização, para que se faça a necessária mediação, no caso concreto, entre interesses públicos. Portanto, do ponto de vista do argumento do empreendedorismo, a prática institucional da agência reguladora de telecomunicações é questionável, dado que, se levado em consideração, o conceito poderia ter produzido um resultado jurídico diverso, interferindo na gradação da concentração regulatória normativa aplicável à atividade em questão. 


\section{Conclusão}

Conforme exposto, a regulação jurídica é um fenômeno fluido, que se faz presente na previsão explícita de regras detalhadas para a prestação de um serviço, na aparente omissão normativa, criadora de espaços de liberdade para definição das regras de prestação de um serviço pelo particular, e no continuum normativo que liga estas duas possibilidades. Cada ponto no referido continuum corresponde ao grau da concentração regulatória normativa aplicável a uma atividade, um serviço específico, ou até mesmo um caso concreto. Em nosso entendimento, o instrumento que move o grau da concentração regulatória normativa é a mediação entre interesses públicos feita pelo Estado, que determina o interesse público para a atividade, o serviço, o caso concreto. Este é o sentido do funcionamento da regulação como gradação da concentração regulatória, fundada no interesse público.

Suposta omissão normativa, concretizada em ausência de previsão regulatória explícita, não pode servir como argumento suficiente para proibir, no caso, as possibilidades técnicas de prestação de um serviço, uma vez que a regra é a liberdade de iniciativa - uma clara expressão jurídica do empreendedorismo. Ou seja, a liberdade de iniciativa é um fundamento jurídico para a prestação do serviço mediante essas ou aquelas possibilidades técnicas, definidas exclusivamente por aquele que empreende. Esta é uma regra que realiza no caso o propósito institucional de fomento ao empreendedorismo, como fonte de produção de riqueza social. Ao mesmo tempo, o empreendedorismo reforça o significado da livre iniciativa, deixando claro quais resultados se espera para a sociedade. Outras relações entre elementos do empreendedorismo e normas jurídicas poderiam ser pensadas, realizando o incentivo à pequena e média empresa, por exemplo. O importante é o foco no propósito institucional comum às regras: o fomento e proteção jurídicos ao comportamento empreendedor, relacionado à inovação, coordenação de demandas do mercado, difusão tecnológica etc.

Identificada a regra que realiza o propósito institucional mencionado para dada situação (a livre iniciativa, por exemplo), o passo seguinte é a avaliação de outros interesses públicos em jogo. Estes podem reforçar, afastar e modificar as consequências jurídicas da regra, ou assumir um significado específico frente à mesma regra. No caso estudado, o princípio da isonomia assumiu o significado específico de igualdade de acesso às informações necessárias para a percepção da oportunidade empreendedora. Em conjunto com o restante da argumentação construída dentro do caso, esse dado permitiu criticar a prática institucional da 
Agência Nacional de Telecomunicações, do ponto de vista do empreendedorismo, do incentivo à competição, da isonomia entre os agentes econômicos prestadores do serviço.

Em outras palavras, o trabalho produziu como resultado a conclusão de que o conceito de empreendedorismo é juridicamente relevante para a gradação da concentração regulatória normativa, e sua aplicação, como se observou no caso analisado, pode produzir impacto no debate a respeito do grau de concentração regulatória normativa devido à prestação de determinado serviço de telecomunicações. Desenvolvimentos posteriores da pesquisa podem apontar outras expressões jurídicas do empreendedorismo, que se relacionem com outros elementos além da livre iniciativa (por exemplo, o fomento à consolidação de pequenas e médias empresas), e como essas expressões se relacionam com princípios de ordem material, como o direito à comunicação e o regime jurídico aplicável ao serviço público.

Entendemos que é a explicitação dessas relações que pode concretizar o que se espera do empreendedorismo, para que se mantenha o foco na produção de riqueza e bemestar para a sociedade, e sejam afastadas iniciativas empreendedoras, em um certo sentido, porém improdutivas para o corpo social. Se reconhecemos que o empreendedorismo não é a tábua de salvação para todos os males, queremos entender como a ordem jurídica e a prática de nossas instituições pode detectá-lo, incentivá-lo e direcioná-lo para o que nos pode ser útil. Muito útil. 


\section{Referências}

AHMAD, Nadim; SEYMOUR, Richard G. Defining Entrepreneurial Activity: Definitions Supporting Frameworks for Data Collection. OECD Statistics Working Papers, No. 2008/1. Paris: OECD Publishing, 2008. 18 p.

BASTOS, Celso Ribeiro. Comentários à Constituição do Brasil. Vol. 7. São Paulo: Saraiva, 1990.

BAUMOL, William J. Entrepreneurship: productive, unproductive, and destructive. In: Journal of Political Economy, Vol. 98, No. 5. Chicago: The University of Chicago Press, 1990. p. 893-921.

CANTILLON, Richard. Essays on the nature of commerce in general. Nova introdução por Antony Brewer. New Brunswick, New Jersey: Transaction Publishers, 2001. 188 p.

CASSON, Mark. The entrepreneur: an economic theory. $2^{\mathrm{a}}$ ed. Cheltenham, UK: Edward Elgar Publishing, 2003. 271 p.

DRUCKER, Peter F. Innovation and entrepreneurship: practice and principles. Oxford: Butterworth-Heinemann, 2007. 253 p.

FERRAZ JÚNIOR, Tércio Sampaio. A economia e o controle do Estado. O Estado de São Paulo. São Paulo, p. 50, 04 jun 1989. apud GRAU, Eros Roberto. A ordem econômica na constituição de 1988 (Interpretação e crítica). 11 a ed. São Paulo: Malheiros, 2006. p. 206-207.

FRANCO, Vera Helena de Mello. Manual de Direito Comercial: o empresário e seus auxiliares, o estabelecimento empresarial, as sociedades. Vol. 1. São Paulo: Editora Revista dos Tribunais, 2004. 310 p.

GRAU, Eros Roberto. A ordem econômica na constituição de 1988 (Interpretação e crítica). $11^{\mathrm{a}}$ ed. São Paulo: Malheiros, 2006. 391 p.

HAYEK, F.A. The use of knowledge in society. In: American Economic Review. Vol. 35, No. 4. Pittsburg: American Economic Association, Setembro, 1945. p. 519-530.

HÉBERT, Robert F.; LINK, Albert N. In the search of the meaning of entrepreneurship. In: Small Business Economics. Vol. 1 No 1. Norwell: Kluwer Academic Publishers, 1989. p. 39- 
49.

HERREN AGUILLAR, Fernando. Controle social de serviços públicos. São Paulo: M. Limonad, 1999. 302 p.

KARKACHE, Sergio. Princípio do tratamento favorecido: o direito das empresas de pequeno porte a uma carga tributária menor. Dissertação (Mestrado em Direito) - Programa de pósgraduação em Direito, Universidade Federal do Paraná, Curitiba, PR, 2009. 296 p.

KIRZNER, Israel M. Competition and Entrepreneurship. Chicago: University of Chicago Press, 1973. 246 p.

KNIGHT, Frank Hyneman. Risk, Uncertainty and Profit. Nova York, NY: Cosimo, 2005. MARQUES NETO, Floriano Peixoto de Azevedo. Regulação estatal e interesses públicos. São Paulo: Malheiros, 2002. 237 p.

MARSHALL, Alfred. Principles of Economics: unabridged eigth edition. Nova York: Cosimo, 2009. $740 \mathrm{p}$.

MELLO, Celso Antonio Bandeira de. Elementos de direito administrativo. São Paulo: Ed. RT, 1991. 382 p.

MONCADA, Luis S. Cabral de. Direito económico. 2. ed. Coimbra: Coimbra Ed, 1988. 433 p.

PASOUR, JR., E. C. Rent Seeking: Some Conceptual Problems and Implications. In: The Review of Austrian Economics. Vol. 1 No. 1. Fairfax County, Virginia: Kluwer Academic Publishers, 1987. p. 123-143. Disponível em: http://mises.org/journals/rae/pdf/rae1_1_8.pdf. Acesso em: 30/11/09.

PENEDER, Michael R. The Meaning of Entrepreneurship: Towards a Modular Concept. WIFO Working Papers, No. 335. Viena: WIFO, Março de 2009. 31 p. Disponível em: http://www.wifo.ac.at/wwa/servlet/wwa.upload.DownloadServlet/bdoc/WP_2009_335\$.PDF. Acesso em: 26/11/09.

SCHULTZ, Theodore W. The Value of the Ability to Deal with Disequilibria. Journal of Economic Literature. Vol. 13, No. 3. Pittsburg: American Economic Association, Setembro, 1975. p. 827-846.

SCHUMPETER, Joseph A. The theory of economic development. New Brunswick, New 
Jersey: Transaction Publishers, 1983. 255 p.

SHANE, Scott Andrews. A General Theory of Entrepreneurship: The Individual-Opportunity Nexus (Série "New Horizons in Entrepreneurship"). Cheltenham, UK: Edward Elgar, 2003. $327 \mathrm{p}$.

STAM, Erik. Entrepreneurship and Innovation. In: STAM, Erik; NOOTEBOOM, Bart (eds.). Micro-Foundations for Innovation Policy. Amsterdam: Amsterdam University Press, 2008. p. 135-172.

SUNDFELD, Carlos Ari. Meu depoimento e avaliação sobre a Lei Geral de Telecomunicações. Revista de Direito de Informática e Telecomunicações, v. 02, 2007. p. 5584.

WENNEKERS, Sander; THURIK, Roy A. Linking Entrepreneurship and Economic Growth. In: Small Business Economics, Vol. 13. Amsterdam: Kluwer Academix Publishers, 1999. p. 27-55. 